\title{
Functional abnormalities in the cerebello-thalamic pathways in an animal model of dystonia
}

Elena Laura Margarint ${ }^{1, \#}$, Hind Baba Aïssa ${ }^{1, \#}$, Andrés Pablo Varani ${ }^{1}$, Romain Sala ${ }^{1}$, Fabien Menardy ${ }^{1}$, Assunta Pelosi ${ }^{2,3,4}$, Denis Hervé ${ }^{2,3,4}$, Clément Léna ${ }^{1}$, Daniela Popa ${ }^{1}$

${ }^{1}$ Neurophysiology of Brain Circuits Team, Institut de biologie de I'Ecole normale supérieure (IBENS), Ecole normale supérieure, CNRS, INSERM, PSL Research University, 75005 Paris, France

${ }^{2}$ Inserm UMR-S 1270, 75005 Paris, France,

${ }^{3}$ Sorbonne Université, Sciences and Technology Faculty, Paris, France,

${ }^{4}$ Institut du Fer à Moulin, 75005 Paris, France

\# These authors contributed equally to this work.

Correspondence should be addressed to D.P (daniela.popa@ens.fr).

One sentence summary: A mouse model of DYT25 dystonia, carrying a Gnal mutation disrupting striatal neurotransmission, exhibits anomalous cerebello-thalamic plasticity in the non-manifesting state, but theta-burst cerebellar stimulations during cholinergic-induced dystonia depress the cerebello-thalamic transmission and reduce the severity of the motor symptoms.

Author contributions: DP, CL and DH acquired funding; ELM, APV and DP conceived and designed the experiments; ELM, HBA, CL and DP wrote the initial manuscript; ELM, HBA, APV, RS, CL analyzed the data; ELM, HBA, APV, RS, FM, AP, DH generated the mouse model and/or performed the experiments. All authors interpreted results, revised the final manuscript, and approved the final manuscript.

Data, code and materials availability: The data and the code for electrophysiological analysis will be made available on the team website upon acceptance: https://www.ibens.ens.fr/spip.php?rubrique53\&lang=en

Acknowledgments: This work was supported by Agence Nationale de Recherche to D.P. and D.H. (ANR16-CE37-0003 Amedyst) and to C.L. (ANR-17-CE37-0009 Mopla) and by the Labex Memolife and the Institut National de la Santé et de la Recherche Médicale (France). The authors declare no competing financial interests. 
Dystonia is often associated with functional alterations in the cerebello-thalamic pathways, which have been proposed to contribute to the disorder by propagating pathological firing patterns to the forebrain. Here, we examined the function of the cerebello-thalamic pathways in a model of DYT25 dystonia, mice carrying a heterozygous invalidation of Gnal gene which notably disrupts striatal function, exhibiting dystonic movements and postures following systemic or striatal administration of oxotremorine. Theta-burst optogenetic stimulations of the cerebellar nuclei evoked a potentiation of the responses to cerebellar stimulations in the thalamus and motor cortex in WT mice, without evident motor function disruption. In contrast, theta burst stimulations evoked a depression of these responses only in dystonia-manifesting Gnal+/- mice after oxotremorine administration, decreased the disabling dystonia attacks, and increased normal active wake behaviour in Gnal+/- mice. The cerebellum could thus offer a gateway for a corrective treatment of motor impairments in dystonia including striatal dysfunction.

Keywords: cerebellum; electrophysiology; optogenetics, Gnal; thalamus, motor cortex; dystonia. 


\section{Introduction}

The purposeful motion of our body is central in the human activity, and neurological diseases altering motor function represent major clinical issues. Dystonias are characterized by involuntary muscle contractions that induce abnormal twisted positions and postures, or cause patterned or stereotyped movements (Albanese et al., 2013). Many primary dystonias have a hereditary component (Breakefield et al., 2008), but the penetrance of genetic forms of dystonia is variable and even in patients carrying identical mutation, symptoms vary in severity, age of onset, focal or generalized localization or progression (Fuchs and Ozelius, 2013; Dufke et al., 2014). This intrinsic variability in dystonia suggests the existence of interacting mechanisms that synergize or cancel out at different levels of the motor centres to determine symptom onset (Hendrix and Vitek, 2012; Prudente et al., 2014; Kaji et al., 2017). (5)

Dysfunctions of the cerebellum and cerebello-cortical pathways have been implicated in dystonia (Neychev et al., 2011; Lehéricy et al., 2013). Patients with various forms of dystonia exhibit structural and functional alterations of the cerebellum as well as abnormalities in the cerebello-thalamic connections (Lehéricy et al., 2013). The relevance of the cerebellum in dystonia has also been demonstrated in animal models (Neychev et al., 2011). In three genetic models of dystonia ( $d t$ rat, tottering mouse and mouse with invalidation of type 1 inositol triphosphate receptor in the cerebellum/brainstem), the removal of the cerebellum, or only of the cerebellar Purkinje neurons or deep cerebellar nuclei (DCN), abolishes dystonic movements (LeDoux et al., 1993; LeDoux et al., 1995; Campbell et al., 1999; Neychev et al., 2008; Hensch et al., 2013). The down-regulation of the DYT1 gene, Torsin A, in the cerebellum is sufficient to trigger dystonia (Fremont et al., 2017). Neurons of the cerebellar nuclei can rapidly excite the dorsolateral striatum through a di-synaptic pathway with a relay in the centro-lateral (CL) nucleus of the thalamus (Chen et al., 2014). Aberrant cerebellar activity can 
cause dystonia by dynamically forcing a pathological state via the cerebello-thalamo-striatal pathway (Calderon et al., 2011). Structural defects in the cerebello-thalamo-cortical pathway have been identified in a mouse model of DYT1 dystonia (Ulug et al., 2011), but they have been proposed to provide a protective effect and limit the penetrance of the disease in patients (Argyelan et al., 2009), consistent with the view that dystonias are brain motor network disorders, where dysfunction of one node results in dysfunctions/adaptations in the others.

$$
\text { dystonia (Fuchs et al., 2013; Vemula et al., 2013; Pelosi et al., 2017), caused by loss-of-function }
$$
mutations of the $G N A L$ gene encoding $G \alpha_{\text {olf }}$, a $G$ protein stimulating adenylate cyclase activity in the striatum. Gnal haplo-deficiency in mice mimics the genetic alterations discovered in DYT25 dystonic patients (Pelosi et al., 2017). Gnal haplo-deficiency reduces striatal cAMP production and disrupts striatal functions but the mice are asymptomatic in terms of dystonia. Dystonic symptoms were generated by injections of a muscarinic cholinergic agonist (oxotremorine $\mathrm{M}$ ) systemically or in the striatum, but not in the cerebellum, indicating that an increase in striatal cholinergic tone is critical to the onset of disorder (Pelosi et al., 2017). The present study is aimed at examining the role of cerebellothalamic tract and its plasticity in this model.

$$
\text { stimulations in the cerebellar dentate nucleus with recordings in the thalamus and motor cortex, and }
$$
with behavioural measures. Moreover, we probed the plasticity induced by cerebellar stimulations using theta-burst stimulation protocols. Indeed, transcranial theta-burst stimulations are used to treat various motor and non-motor disorders (Suppa et al., 2016; Jannati et al., 2017). When administered on the cerebellar cortex, they induce lasting changes of motor cortex excitability (Popa et al., 2010; Gallea et 
al., 2013). Here, we investigated the behavioural and neurophysiological impacts of dentate nucleus (DN) low frequency or theta-burst frequency optogenetic stimulation on the centro-lateral (CL), ventroanterior-lateral (VAL) thalamus, and motor (M1) cortex in both the pre-symptomatic (saline injection), and symptomatic states (oxotremorine injection), of Gnal+/- animal model of dystonia.

Results:

Gnal+/- mice do not have a constitutive locomotor impairment

Young 3 to 7-month-old mice Gnal+/- mice are asymptomatic (Pelosi et al., 2017) and to further verify that they do not exhibit constitutive motor deficit we performed a set of locomotor experiments including vertical pole, horizontal bar, grid test, fixed speed rotarod, gait test and an open-field test (Figure 1). Overall, we did not observe major motor deficits; however, mild effects were noted when the analysis was performed separately on males and females as reported below. A total of 16 Gnal+/- mice were studied, 12 males and 4 females. Regarding the wild-type (WT) mice, 19 mice were studied, 11 males and 8 females.

We observed that the motor performance of Gnal+/- mice was not impaired in the vertical pole test (Mann-Whitney test; $p=0.176$ for males; $p=0.246$ for females), horizontal bar test (Mann-Whitney test; $p=0.487$ for males; $p=0.134$ for females) and grid test (Mann-Whitney test; $p=0.164$ for males; $p$ $=0.298$ for females).

We also performed a fixed speed rotarod test to test the motor coordination. We did not find significant differences between Gnal+/- and WT mice (Repeated measure ANOVA $F(1,4)=7.348 p=$ 0.053), nor when comparing males and females for each speed steps (Student's T test Welsch corrected, with a Bonferroni correction for multitests, $p=0.171$ for both males and females). 
We performed the gait test and different parameters were computed. We were not able to find

121 significant differences in gait width (Mann-Whitney test; $p=0.154$ for males; $p=0.074$ for females), 122 alternation coefficient (Mann-Whitney test; $p=0.391$ for males; $p=0.175$ for females), linear 123 movement (Mann-Whitney test; $p=0.221$ for males; $p=0.101$ for females) or sigma (Mann-Whitney 124 test; $p=0.488$ for males; $p=0.134$ for females). However, the length of stride was significantly longer in 125 Gnal+/- females compared to female WT mice (Mann-Whitney test; $p=0.007$ for females; $p=0.322$ for 126 males).

We also studied both the average locomotor speed and the total distance travelled during an open-field session. We observed no significant differences when comparing Gnal+/- and WT males 129 (Mann-Whitney test; $p=0.141$ for the average speed; $p=0.203$ for the distance travelled). However, we observed that both average speed and distance travelled were lower in females Gnal+/- compared to females WT (Mann-Whitney test; $p=0.037$ for the average speed; $p=0.037$ for the distance). In conclusion, motor activity and motor coordination are not dramatically impaired in young 3 to 7-month-

133 old mice Gnal+/- mice as previously described (Pelosi et al., 2017); however, mild differences were 134 observed in females only, raising the possibility of higher susceptibility in female mice. 

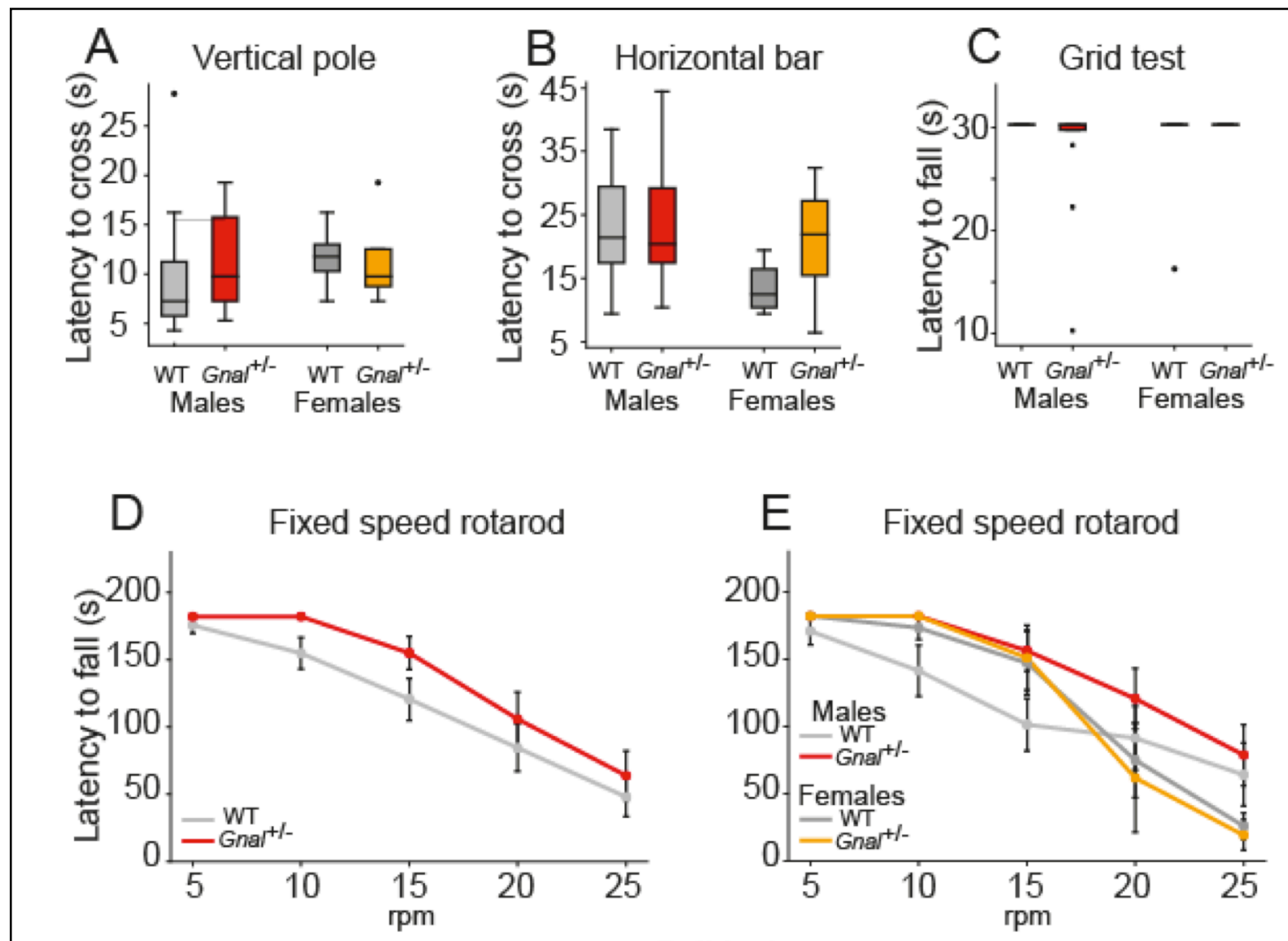
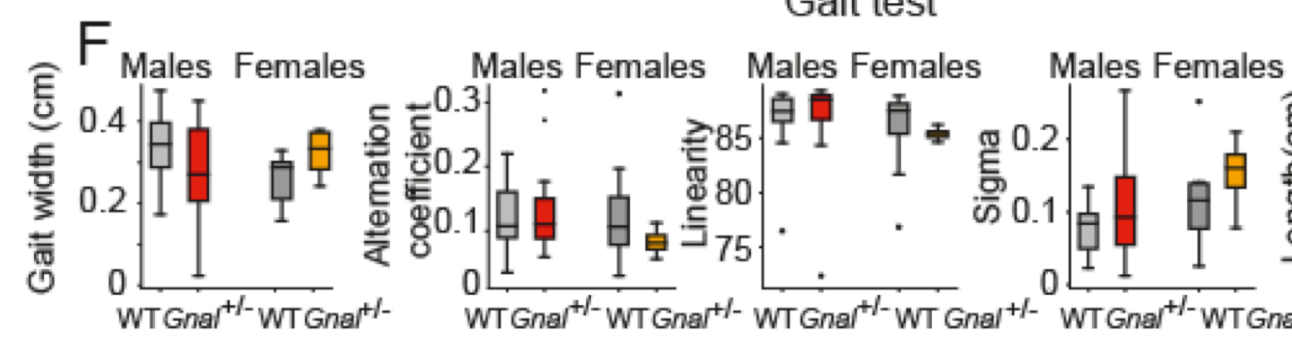

Gait test

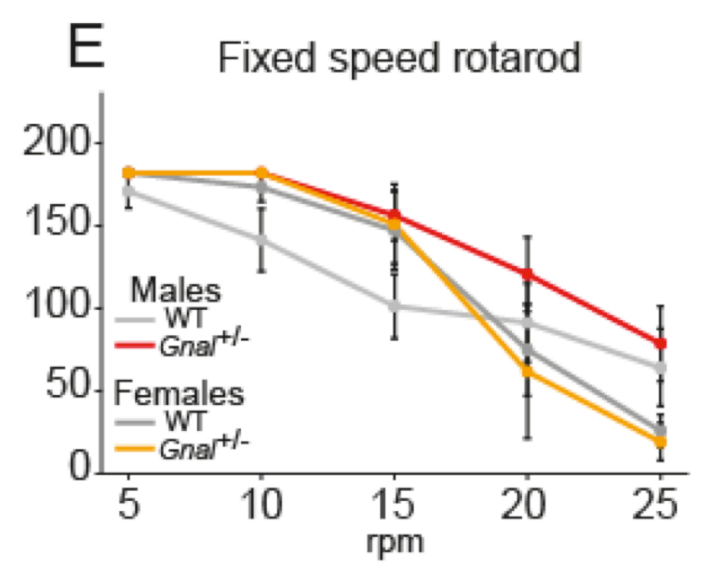

\section{G}

Open-field examples
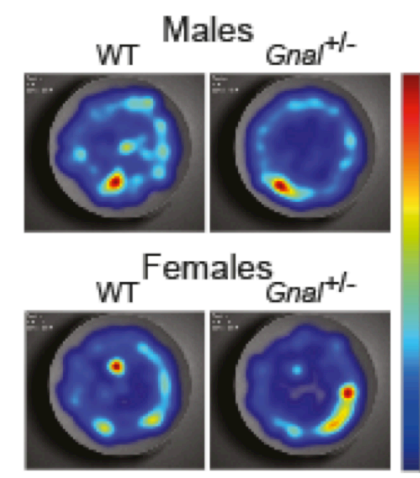
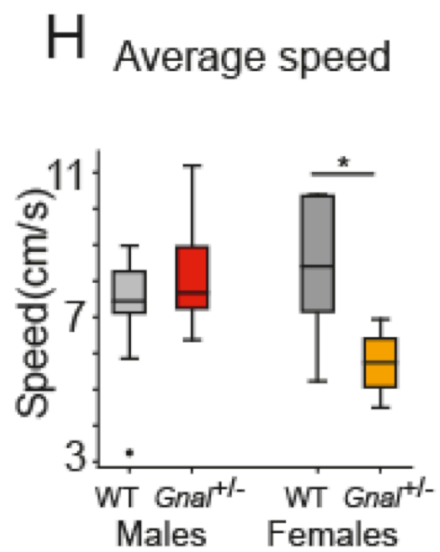

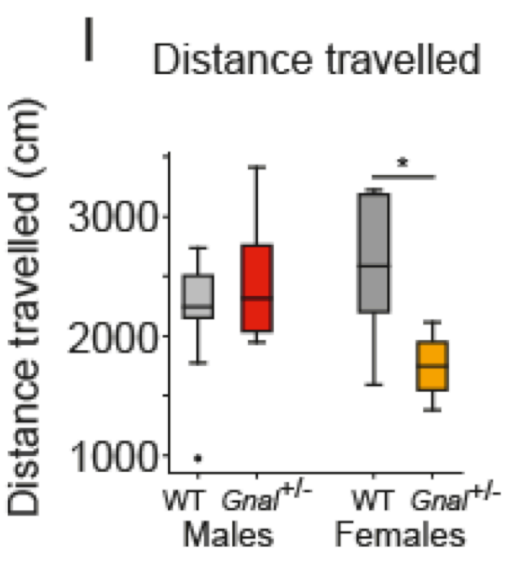

Figure 1. Locomotor activity and motor coordination in Gnal+/- mice. (A) Latency to cross the vertical pole; Mann-Whitney test. (B) Latency to cross the horizontal bar; Mann-Whitney test. (C) Latency to fall during the grid test with a 30s cut-off; Mann-Whitney test. (D) Latency to fall during the fixed speed rotarod test; Repeated measure ANOVA. (E) Latency to fall during the fixed speed rotarod test with groups separated by gender and genotype; Welch corrected Student's t test for each speed step, corrected for multitests using Bonferroni's method. (F) Gait width, alternation coefficient, movement linearity, sigma and stride length during the gait test; Mann-Whitney test ${ }^{*} p<0.05$; ${ }^{*} p<0.01$ (G) Example of heatmaps showing the position of mice during open-field sessions. Average speed $(\mathbf{H})$ and total distance travelled (I) during an open-field session; Mann-Whitney test ${ }^{*} p<0.05 ;{ }^{* *} p<0.01$. 
137 Thalamic and cortical activity, and coupling of the cerebellum to forebrain motor circuits in Gnal+/138 mice

139 The thalamus is the main gateway to the motor cortex and striatum, which are, together with the 140 cerebellum, the main structures involved in dystonia. To examine the impact of the reduction of Gnal 141 expression in the thalamus, we first examined the changes in neuronal activity in the motor thalamus 142 (VAL), the striatum-projecting thalamus $(\mathrm{CL})$ and the motor cortex (M1) in freely moving mice (Figure 2, 143 Table 1). Saline injections in Gnal+/- mice did not induce abnormal motor patterns, consistent with 144 previous observations (Pelosi et al., 2017). In these mice, we found no difference as compared to saline145 injected wild type (WT) mice in the baseline firing rate of thalamic or cortical neurons (Figure 2E, ANOVA 146 repeated measure VAL: $F(1,16)=0.19, p=0.67, C L: F(1,21)=0.21, p=0.65, M 1: F(1,23)=0.033, p=0.86$; no 147 difference was found when males and females were separated).

\begin{tabular}{|c|c|c|c|c|c|c|c|c|}
\hline \multicolumn{1}{c|}{} & \multicolumn{4}{c|}{ FR analysis } & \multicolumn{3}{c|}{ Cb stim analysis } \\
\cline { 2 - 10 } \multicolumn{1}{c|}{} & \# cells & \# mice & \multicolumn{2}{c|}{ \# cells } & \multicolumn{2}{c|}{ \# mice } \\
\hline region & WT & HET & WT & HET & WT & HET & WT & HET \\
VAL & 179 & 221 & 8 & 10 & 23 & 21 & 3 & 4 \\
CL & 236 & 194 & 12 & 11 & 31 & 27 & 5 & 3 \\
M1 & 210 & 237 & 13 & 12 & 37 & 54 & 5 & 5 \\
\hline
\end{tabular}

Table 1. Number of cells used in the analysis of baseline firing rate (Figure 2E) and of responses to 149 cerebellar stimulation (Figure 3C,D,G,H). 


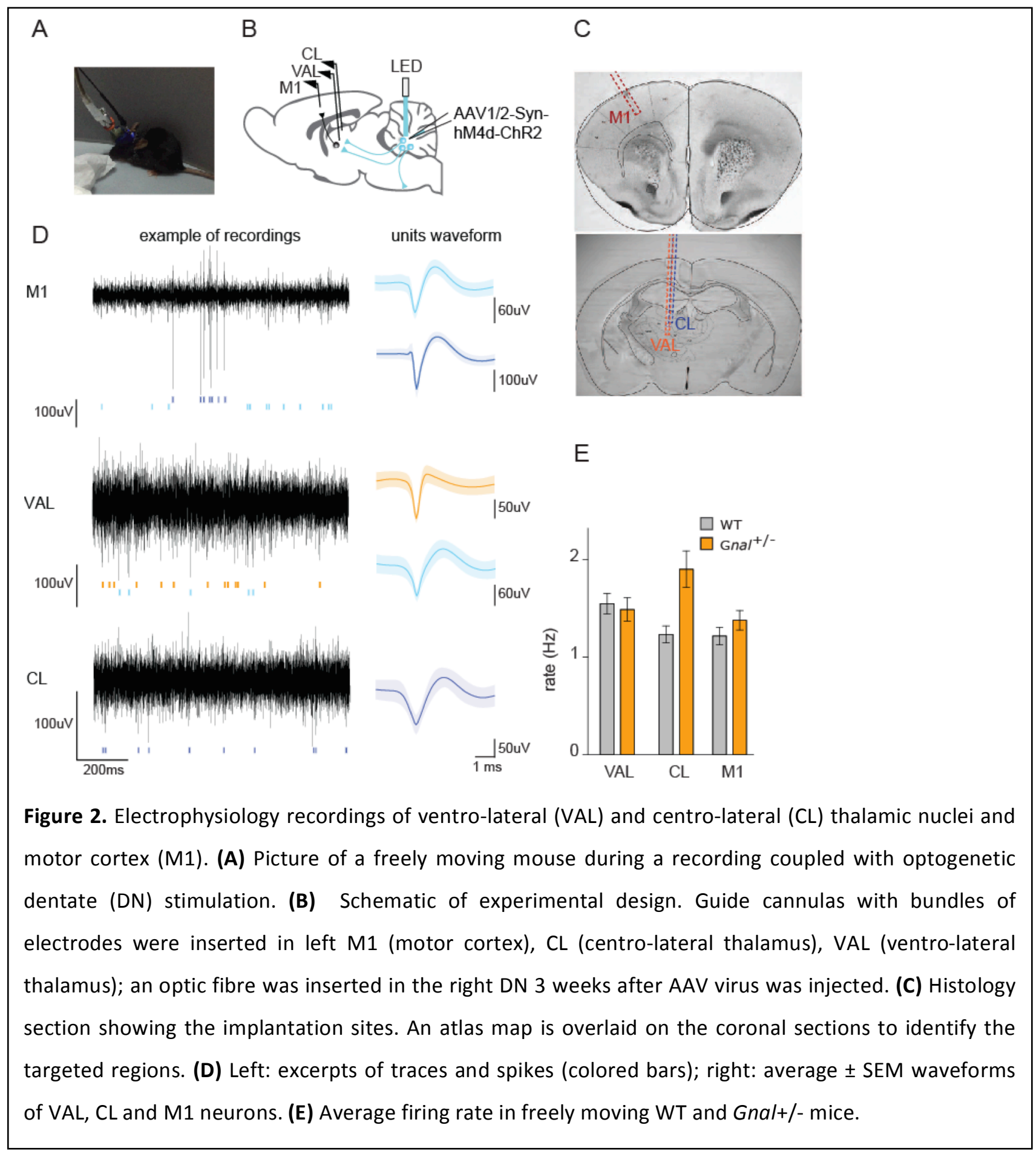

E

To probe the functional drive of the cerebellum on these regions, we expressed channelrhodopsin 2 (ChR2) into DN neurons using an AAV viral strategy (AAV2/1.hSyn.ChR2(H134R)eYFP.WPRE.hGH), and stimulated these neurons through an optical fibre implanted above the DN

(Figure 2B, 2). We first applied simple low-frequency deep cerebellar stimulations $(100 \mathrm{~ms}, 0.25 \mathrm{~Hz}$, 
$1560.9 \mathrm{~mW}$ at the fibre entry), and we found an overall increase in firing rate of about $5 \mathrm{~Hz}$ during the

157 stimulation in all recorded regions in WT and in Gnal+/- saline-injected mice. We did not detect any

158 significant difference between the genotypes (Figure 3C, ANOVA with repeated measure in mice: CL:

$159 F(1,6)=1.057, p=0.343), V A L: F(1,5)=1.466, p=0.28, M 1: F(1,8)=0.0395, p=0.847)$. We then performed

160 oxotremorine $M$ administration $(0.1 \mathrm{mg} / \mathrm{kg}$, i.p.) and observed an increase in the evoked responses to

161 cerebellar stimulation in all the structures studied in both the WT and Gnal+/- genotypes (Figure 3G,

162 Table 2). 


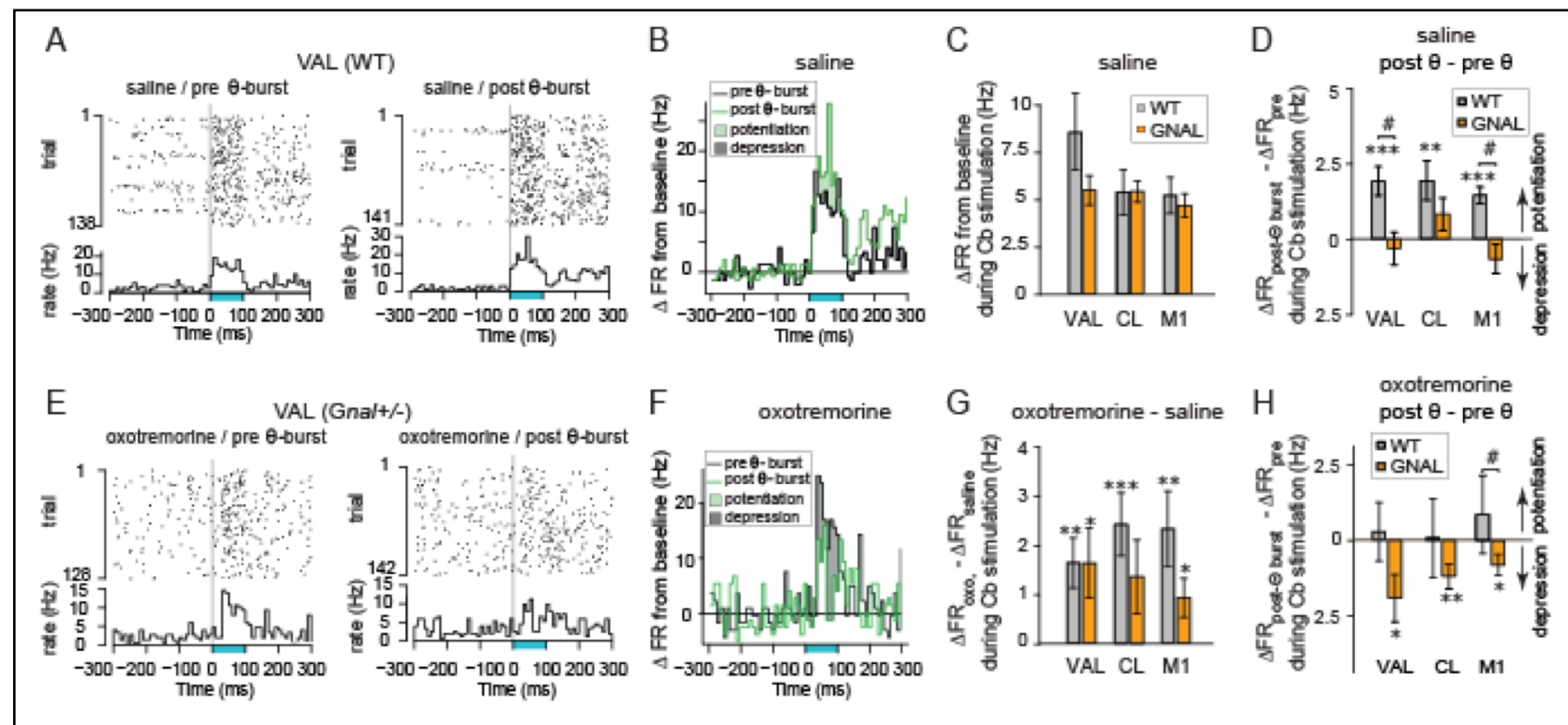

Figure 3. Effect of low-frequency and theta-burst cerebellar stimulations on the firing rate in saline and oxotremorine conditions in VAL, CL and M1 of WT and Gnal+/- mice. On the first day, we examined the effects of low frequency opto-stimulations (blue line, $100 \mathrm{~ms}, 0.25 \mathrm{~Hz}$ ) on the firing rate of neurons in the various brain regions after saline and oxotremorine administrations. On the following day, the effects of the same low frequency stimulation were compared before and after $\theta$-burst stimulations $(20 \mathrm{~ms}, 8,33 \mathrm{~Hz}$, applied for $2 \times 40$ s with a 2 min pause in between) after saline and oxotremorine administrations. (A) Raster and peristimulus time histogram (PSTH, bin $10 \mathrm{~ms}$ ) for one VAL neuron from a WT mouse before (left) and after (right) theta-burst stimulation in saline condition; the PSTH are normalized to express a firing rate (see Methods). (B) Overlay of the PSTHs from the panel A; the difference between the histograms is filled to evidence the potentiation or depression of the responses. In this case potentiation prevails. See Table 1 for number of cells/mice used. (C) Increase in firing rate (relative to the baseline firing rate) induced by $100 \mathrm{~ms}$ DN nucleus stimulations in WT and Gnal+/- animals. (D) Impact of thetaburst stimulations administered in saline condition on the response to $100 \mathrm{~ms}$ DN stimulation. Note the absence of potentiation in Gnal+/- mice. (E) (F) same as (A) and (B) respectively, for a VAL neuron from a Gnal+/- mouse before and after theta-burst stimulation in the oxotremorine condition. (G) effect of oxotremorine administration on the response to cerebellar stimulations. (H) Impact of theta-burst stimulations on the response to $100 \mathrm{~ms}$ DN stimulation (same as (D)) in the oxotremorine condition. See Table 2 for corresponding repeated measures ANOVAs. ${ }^{*} p<0.05, * * p<0.01, * * * p<0.001$ paired difference between conditions for the cells, ${ }^{p} p<0.05$ difference between Gnal+/- and WT mice. Error bars represent SEM.

To examine the plasticity of the cerebello-thalamic pathways, we then studied the impact of 
studied separately). In the saline condition, the response to low-frequency stimulations was significantly increased in $\mathrm{CL}$, VAL (Figure $3 \mathrm{~A}, \mathrm{~B}$ ) and $\mathrm{M} 1$ after theta-burst stimulations in the wild type mice, while no significant change was found in the Gnal+/- mice (Figure 3D, Table $1 \& 2$ ). The difference between wild type and Gnal+/- mice was clearly significant in VAL and M1 (Figure 3D, Table 1 \& 2). In contrast, following oxotremorine administration, the responses to cerebellar low-frequency stimulations were not changed in wild type mice after theta-burst stimulations, while they were decreased in Gnal+/- mice in all the structures considered : $\mathrm{CL}$, VAL (Figure 3E,F) and M1 (Figure 3H, Table 1 \& 2), suggesting a weaker entrainment of the motor circuit by the cerebellum during dystonic-like attacks induced by oxotremorine in Gnal+/- mice. The increase (potentiation) (Figure 3A,B) or decrease (depression) (Figure $3 E, F)$ in firing rate were observed throughout the duration of the stimulation (Figure 3B,F).

\begin{tabular}{|c|c|c|c|c|}
\hline \multirow[b]{2}{*}{ TREATMENT } & \multirow[b]{2}{*}{ CONDITION } & \multicolumn{2}{|c|}{ REGION RECORDED } & \multirow[b]{2}{*}{ M1 } \\
\hline & & VAL & $\mathrm{CL}$ & \\
\hline \multirow[t]{3}{*}{ Oxotremorine } & WT & $\begin{array}{c}F(1,22)=10.38 \\
P=0.003928\end{array}$ & $\begin{array}{l}F(1,30)=14.45 \\
P=0.0006566\end{array}$ & $\begin{array}{c}F(1,36)=9.025 \\
P=0.004824\end{array}$ \\
\hline & GNAL +/- & $\begin{array}{c}F(1,20)=5.184 \\
P=0.03394\end{array}$ & $\begin{array}{c}F(1,26)=3.301 \\
P=0.08076\end{array}$ & $\begin{array}{c}F(1,53)=5.283 \\
P=00255\end{array}$ \\
\hline & Genotype $\neq$ & $\begin{array}{c}F(1,40)=0.1006 \\
P=0.7527\end{array}$ & $\begin{array}{c}F(1,51)=1.214 \\
P=0.2758\end{array}$ & $\begin{array}{c}F(1,80)=0.2567 \\
P=0.6138\end{array}$ \\
\hline \multirow[t]{3}{*}{ Saline $+\theta$-burst } & WT & $\begin{array}{l}F(1,22)=16.11 \\
P=0.0005835\end{array}$ & $\begin{array}{c}F(1,30)=8.812 \\
P=0.005834\end{array}$ & $\begin{array}{c}F(1,36)=27 \\
P=8.229 \mathrm{e}-06\end{array}$ \\
\hline & GNAL+/- & $\begin{array}{c}F(1,20)=0.3588 \\
P=0.5559\end{array}$ & $\begin{array}{c}F(1,26)=2.258 \\
P=0.145\end{array}$ & $\begin{array}{c}F(1,53)=1.96 \\
P=0.1674\end{array}$ \\
\hline & Genotype $\neq$ & $\begin{array}{c}F(1,37)=4.791 \\
P=0.03499\end{array}$ & $\begin{array}{c}F(1,48)=0.2916 \\
P=0.5917\end{array}$ & $\begin{array}{c}F(1,78)=4.047 \\
P=0.04771\end{array}$ \\
\hline \multirow[t]{3}{*}{ Oxo+ $\theta$-burst } & WT & $\begin{array}{c}F(1,22)=0.0858 \\
P=0.7723\end{array}$ & $\begin{array}{c}F(1,30)=0.003561 \\
P=0.9528\end{array}$ & $\begin{array}{c}F(1,36)=0.442 \\
P=0.5104\end{array}$ \\
\hline & GNAL+/- & $\begin{array}{c}F(1,20)=5.928 \\
P=0.0244\end{array}$ & $\begin{array}{c}F(1,26)=8.154 \\
P=0.008334\end{array}$ & $\begin{array}{c}F(1,53)=5.459 \\
P=0.02329\end{array}$ \\
\hline & Genotype $\neq$ & $\begin{array}{c}F(1,40)=2.681 \\
P=0.1094\end{array}$ & $\begin{array}{c}F(1,53)=0.3898 \\
P=0.5351\end{array}$ & $\begin{array}{c}F(1,84)=5.075 \\
P=0.02688\end{array}$ \\
\hline
\end{tabular}

Table 2. Repeated measure ANOVA for the increase in firing rate induced by low-frequency dentate stimulations in the VAL and $\mathrm{CL}$ thalamus, and motor cortex $\mathrm{M} 1$ in saline/oxotremorine conditions and before/after theta-burst stimulations.

Beneficial effect on motor activity of the optogenetic stimulation in the cerebellar dentate nucleus of Gnal+/- mice

Taking advantage of chronic implanted animals, we then evaluated the dystonic behaviour in Gnal+/- compared to WT mice using an abnormal motor score (Fremont et al., 2017; Pelosi et al., 2017; White and Sillitoe, 2017). Saline-injected Gnal+/- and WT mice showed no signs of dystonia; in contrast, 
the muscarinic cholinergic agonist, oxotremorine $M(0.1 \mathrm{mg} / \mathrm{kg})$, consistently induced abnormal

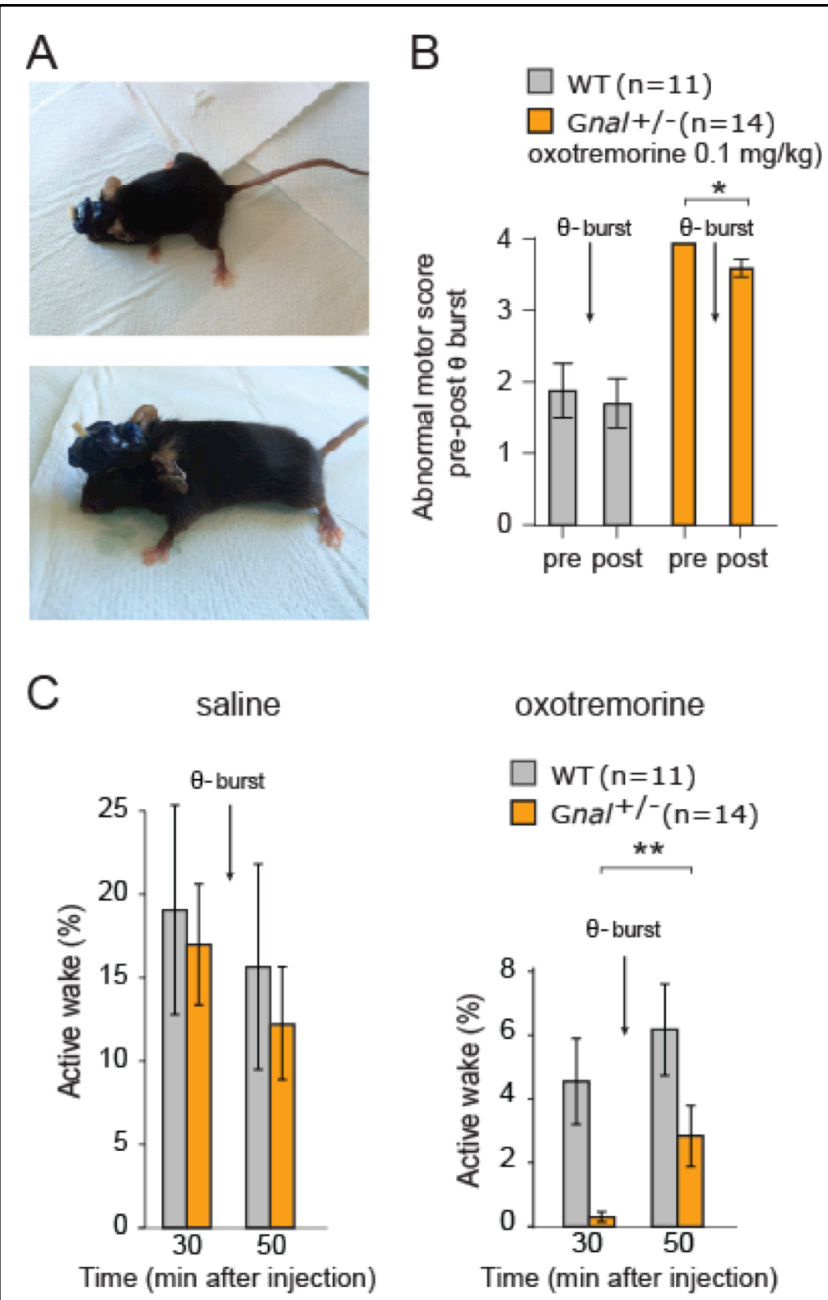

Figure 4. Motor behaviour of Gnal+/- (orange) and wild type (WT) mice (grey). (A) Examples of dystonic postures in Gnal+/- mice following oxotremorine administration. (B) Average dystonia scores in Gnal+/and WT mice following oxotremorine administration before and after dentate nucleus (DN) theta burst stimulation (C) Change of average active wakefulness percentage after DN theta burst stimulation in Gnal+/- and WT mice after saline or oxotremorine administration. Data were analysed by Student $\mathrm{t}$ test. ${ }^{*} p<0.05, * * p<0.01$ difference between pre and post theta-burst stimulations. Error bars represent SEM. 
To test the impact of cerebellar stimulations on abnormal movements, the evolution of dystonic-

190

191

192

193

194

195

196

197

like movements and postures was evaluated before and after the DN optogenetic theta stimulations

(Figure 4A,B). DN optogenetic theta-burst stimulations decreased the abnormal motor behaviour in Gnal+/- mice following oxotremorine M challenge (Wilcoxon matched-pairs signed rank test; $\mathrm{P}=0.0313$ ).

To confirm these observations, we also evaluated the activity of the mice by measuring the percentage of time spent moving in an open-field ("active wakefulness") (Georgescu et al., 2018). In the salinetreated wild type mice, DN optogenetic theta burst stimulations had no significant effect (30 to $50 \mathrm{~min}$ after saline injection) on the active wake time. Similarly, in the saline-treated Gnal+/- mice, theta-burst stimulation did not significantly change the active wake time (Figure $4 C$ ). In contrast, in the oxotremorine condition, the average active wake time decreased in both wild type and Gnal+/- mice compared to saline, the effect being more marked in the mutant mice (Figure 4C). One session of DN optogenetic theta-burst stimulation was sufficient to significantly increase the wake time in Gnal+/mice $(p=0.0099)$ while the increase remained non-significant in wild type mice (Figure 4C). Overall, these results indicate that DN optogenetic theta-burst stimulations decrease the "dystonic" phenotype in oxotremorine-treated Gnal+/- mice regarding both the abnormal motor scores and locomotor activity deficit.

Overall, these results indicate a functional impairment of cerebello-thalamo-cortical pathway in Gnal+/mice, which is revealed by a loss of potentiation following theta-burst stimulations in saline conditions. These stimulations decrease cerebello-thalamic connectivity during dystonic-like attacks in Gnal+/- mice and reduced the dystonic signs. 


\section{Discussion}

In the present study, we investigated the behaviour and functional coupling of the dentate (DN) nucleus of cerebellum to the thalamus and motor cortex M1 in basal condition and during dystonic-like state triggered pharmacologically in the Gnal+/- animal model. We confirmed the presence of dystoniclike movements and postures in these mutant mice after oxotremorine, a muscarinic cholinergic agonist. We found little if any change in locomotor activity or motor coordination and in baseline firing rate in the thalamus and M1 cortex between Gnal+/- and control mice. Theta-burst cerebellar DN stimulations induced potentiation of cerebello-thalamic pathways in wild type mice, but not in Gnal+/- mice suggesting a functional alteration of the cerebello-thalamic pathways in these mice. In contrast, thetaburst stimulation of cerebello-thalamic pathway induced a depression of the cerebello-thalamic connections after oxotremorine administration in Gnal+/- mice (but not in WT mice). Such changes might prevent the propagation of the abnormal activity of the cerebellum to motor circuits in the Gnal+/- mice in oxotremorine condition. Indeed, theta-burst stimulation of the DN cerebellar nucleus decreased oxotremorine-induced dystonic-like motor abnormalities and increased normal active behaviour (active wakefulness) in Gnal+/- mice.

\section{Dystonia and cerebello-thalamic pathways}

Despite the strength of the association between dystonia and basal ganglia (BG) demonstrated by numerous studies in both patients and animals (Köhling et al., 2004; Hallett, 2006; Fujita and Eidelberg, 2017; Simonyan et al., 2017; Huebl et al., 2018), the advances in neuroimaging approaches and electrophysiology have provided evidence that regions outside the BG are also involved. The dystonia should then be viewed as a "circuit disorder" (Lehéricy et al., 2013) spreading over a network 
of brain motor regions. It is now established that the cerebellum is part of this network, since compelling evidence shows that disruption of cerebellar output causes dystonia (Pizoli et al., 2002; Raike et al., 2013). Abnormal cerebellar nuclei bursting activities were observed in several animal models of dystonia such as DYT1 (Fremont et al., 2017) Tewari et al., 2017), genetic disruption of the olivocerebellar circuit (White and Sillitoe, 2017) or Na+/K+-ATPase $\alpha 3+/ D 801 Y$ mutant mice (Fremont et al., 2015; Isaksen et al., 2017). These activities are thought to rely on a pathway joining the cerebellum to the CL thalamus and striatum to propagate pathological activities (Calderon et al., 2011). This cerebellothalamo-striatal pathway seems to be a key player in such forms of dystonia: imaging studies in DYT1 and DYT6 gene carriers and patients suggested a decreased connectivity between the cerebellum and thalamus and a disruption of cerebellum output that could play a significant role in the appearance of the dystonia (Carbon et al., 2008; Argyelan et al., 2009). If cerebellar dysfunction may disrupt basal ganglia function, the reverse has received little attention so far.

Here we studied the Gnal+/- mouse model of the adult-onset dystonia DYT25 (Pelosi et al., 2017). The Gnal gene encodes the $\alpha$ subunit of the heterotrimeric G-protein Golf, which is an essential relay in dopamine and adenosine transmission onto the adenylyl cyclase in the striatum. Gnal+/- mice are also characterized by abnormal responses of striatal cholinergic interneurons (Eskow Jaunarajs et al., 2019). Despite the reduced production of striatal CAMP in these mice, we found no innate motor impairment in Gnal+/- mice for males and only a mild difference for females, in various motor tests (vertical pole, horizontal bar, grid test, fixed speed rotarod, gait test and open-field locomotor experiments). Therefore, these mice exhibit no overt motor deficit in baseline condition, which may correspond to a 'presymptomatic' state. Oxotremorine injections in these mice -performed either systemically or locally into the striatum- induce strong dystonic-like syndrome compared to wild type mice(Pelosi et al., 2017). Under oxotremorine, these mice are likely representing a model of dystonia 
caused by striatal primary dysfunction, offering an opportunity to examine the function of the cerebellothalamic connection in such model.

We did not find any differences in the spontaneous firing activity between wild type and Gnal+/mice in $\mathrm{CL}$ and VAL thalamus or $\mathrm{M} 1$ cortex, indicating an absence of overt baseline deficits. Oxotremorine injections mildly increased the average firing rate in all structures, but there was no strong difference between wild type and Gnal+/- mice. Examining the activity evoked in these brain regions by cerebellar stimulation failed also to reveal overt differences, although changes in cerebellothalamic efficiency might be concealed by the variability of parameters of the experiments (e.g. variability in ChR2 expression, in optical fiber positioning). Indeed, our plasticity experiments using theta-burst stimulations in the DN nucleus of the cerebellum revealed clear differences in the cerebellothalamic pathway of Gnal+/- mice, with a lack of potentiation in the saline condition, and a depression not observed in wild type mice- in the oxotremorine condition. These results suggest a saturation of potentiation of the cerebello-thalamic pathway of Gnal+/- mice, which could be reversed by stimulations in the oxotremorine condition. Such changes in plasticity and saturation are also found in the striatum in motor disorders (Calabresi et al., 2016). These anomalous plasticities might result from compensatory alterations to the striatal dysfunction induced by oxotremorine in Gnal+/- mice (Pelosi et al., 2017). Our results are consistent with those of White and Sillitoe (2017), who demonstrated in a model of dystonia caused by silencing the olivo-cerebellar transmission, that high frequency electrical stimulations of the interposed cerebellar nuclei decreased the dystonia-like behaviour of mice, an effect reproduced by cerebellar lidocaine inhibition consistent with an inhibitory effect of stimulations (White and Sillitoe, 2017). 


\section{Cerebellar theta-burst stimulations and dystonia}

The rationale of using theta-burst stimulation derives from human studies, where lasting changes in excitability have been shown to be induced by such stimulations (Huang et al., 2005). Transcranial cerebellar stimulations are known to affect within few milliseconds both the inhibition and excitation in the motor cortex networks (Daskalakis et al., 2004), presumably via the di-synaptic excitatory connection linking the cerebellum to the motor cortex via the ventral thalamus (Allen and Tsukahara, 1974; Iwata and Ugawa, 2005). Theta-burst protocols applied to the cerebellum have then been found to induce long-lasting changes in motor response to motor cortex stimulations (Koch et al., 2008).

Cerebellar stimulations in dystonic patients have been mostly performed in the context of focal dystonia (cervical or hand) with good results for cervical dystonia. During a sham-controlled trial on cervical dystonic patients, Koch et al. have applied two-weeks of continuous theta-burst stimulation (TBS) and transcranial magnetic stimulation (TMS) and reported a clinical improvement of $15 \%$ at the end of the trial (Koch et al., 2014). No effect was observed in hand focal dystonia (Hubsch et al., 2013; Linssen et al., 2015; França et al., 2018), but an insufficient number of repetition may be responsible for the lack of effect (Meunier et al., 2015). The stimulations are administered on the cerebellar cortex, so the site(s) of plasticity responsible for the improvement of the patient's condition is unknown. In healthy individuals, transcranial cerebellar stimulations modulate the cortical plasticity in a paired-associative stimulation (PAS) paradigm (Hamada et al., 2012), and theta burst cerebellar stimulations may modulate the PAS remotely in time (Popa et al., 2013), indicating that the cerebellum controls cortical plasticity. Interestingly in patients with cervical dystonia, the impact of cerebellar manipulations on cortical plasticity was reversed compared to healthy controls (Popa et al., 2018). Our experiments suggest that theta-burst stimulations may also impact the cerebello-thalamic pathway, but as in cervical dystonia (Popa et al., 2018), stimulations reversing the cerebello-thalamic plasticity anomaly improve the mouse motor function, suggestive that manipulations aimed at recruiting cerebello-thalamic plasticity could be 
a relevant therapeutic strategy.

\section{Control of striatal cholinergic interneurons by thalamo-striatal inputs (BG-CB interaction)}

The striatum has been shown to receive di-synaptic inputs from the cerebellum (Bostan et al., 2013), and these inputs are presumably relayed to a large part through the intralaminar thalamus $\mathrm{CL}$ (Ichinohe et al., 2000; Chen et al., 2014). These nuclei also send strong projections to the dorsal striatum while only modestly contributing to the innervation of the cerebral cortex (Smith et al., 2014). The principal synaptic targets of the thalamic nuclei in the striatum are the dendritic spines of the medium spiny neurons (MSNs), but they also engage cholinergic interneurons in a feed-forward regulation that differentially control the populations of MSNs expressing the D1 dopamine receptors and exerting prokinetic effect, and the MSNs expressing the D2 receptors and exerting an anti-kinetic effect (Ding et al., 2010). Brief stimulations of thalamic input generate in cholinergic interneurons, a burst-pause firing pattern that transiently suppresses cortical drive of the two types of MSNs and then creates a secondlong period in which activity in D2-expressing MSNs is increased, producing a potent suppression of action. Since salient sensory stimuli activate intralaminar thalamic neurons, Surmerier and coll. proposed that these processes could be a key component of the physiological responses elicited in the striatum by salient sensory stimuli (Ding et al., 2010; Smith et al., 2014). These responses would produce a cessation of ongoing motor activity and later enable switching to different actions. Interestingly, in mice with the DYT1 dystonia mutation, brief stimulations of thalamo-striatal inputs, mimicking an effect of salient events, evoke abnormal responses in cholinergic interneurons, leading to an altered corticostriatal synaptic activity of MSNs (Sciamanna et al., 2012). However, these abnormalities are probably related to a predisposition to dystonia rather than to dystonia manifestations since the animal model is essentially asymptomatic. In the Gnal+/- dystonia model, the dystonic state is induced by a cholinergic pharmacological activation (Pelosi et al., 2017), which likely produces a severe imbalance in the 
329 activities of the two populations of MSNs. The "anti-dystonic" effects we induced by stimulations of 330 cerebellar output in the dentate nucleus of Gnal+/- mice might rely on a reduction of these alterations. 331 However, understanding the mechanisms at play will probably require solving the complex rules of 332 synaptic plasticity in the striatum (reviewed in Perrin and Venance, 2019).

In conclusion, our study investigates an original model of dystonia that mimics the genetic 334 alterations discovered in DYT25 dystonic patients, a subtype of dystonia that has not yet been studied in 335 detail. Despite the fact that the striatum is likely the primary origin of functional alterations (Pelosi et al., 336 2017), our study revealed abnormalities in cerebello-thalamic pathways in Gnal+/- mice with different 337 plasticity properties in asymptomatic mice (in which dysfunctions are compensated) and during 338 dystonia-like state (in response to oxotremorine). The identification of patterns of cerebellar stimulation 339 maximizing the depression of the cerebello-thalamic pathway could thus potentially improve the 340 strategies for therapeutic interventions in patients. 


\section{References}

Albanese A, Bhatia K, Bressman SB, DeLong MR, Fahn S, Fung VSC, Hallett M, Jankovic J, Jinnah A, Klein C, Lang AE, Mink JW, Teller JK (2013) Phenomenology and classification of dystonia: A consensus update. Movement Disorders 28:863-873.

Allen GI, Tsukahara N (1974) Cerebrocerebellar. Cerebrocerebellar communication systems 54.

Argyelan M, Carbon M, Niethammer M, Ulug AM, Voss HU, Bressman SB, Dhawan V, Eidelberg D (2009) Cerebellothalamocortical Connectivity Regulates Penetrance in Dystonia. Journal of Neuroscience 29:9740-9747.

Bostan AC, Dum RP, Strick PL (2013) Cerebellar networks with the cerebral cortex and basal ganglia. Trends in Cognitive Sciences 17:241-254.

Breakefield XO, Blood AJ, Li Y, Hallett M, Hanson PI, Standaert DG (2008) The pathophysiological basis of dystonias. Nature Reviews Neuroscience 9:222-234.

Calabresi P, Pisani A, Rothwell J, Ghiglieri V, Obeso JA, Picconi B (2016) Hyperkinetic disorders and loss of synaptic downscaling. Nature neuroscience 19:868-875.

Calderon DP, Fremont R, Kraenzlin F, Khodakhah K (2011) The neural substrates of rapid-onset DystoniaParkinsonism. Nature neuroscience 14:357-365.

Campbell DB, North JB, Hess EJ (1999) Tottering mouse motor dysfunction is abolished on the Purkinje cell degeneration (pcd) mutant background. Experimental Neurology 160:268-278.

Carbon M, Ghilardi MF, Argyelan M, Dhawan V, Bressman SB, Eidelberg D (2008) Increased cerebellar activation during sequence learning in DYT1 carriers: an equiperformance study. Brain 131:146-154.

Chen $\mathrm{CH}$, Fremont R, Arteaga-Bracho EE, Khodakhah K (2014) Short latency cerebellar modulation of the basal ganglia. Nature neuroscience 17:1767-1775.

Daskalakis ZJ, Paradiso GO, Christensen BK, Fitzgerald PB, Gunraj C, Chen R (2004) Exploring the connectivity between the cerebellum and motor cortex in humans. Journal of Physiology 2:689-700.

Ding JB, Guzman JN, Peterson JD, Goldberg JA, Surmeier DJ (2010) Thalamic gating of corticostriatal signaling by cholinergic interneurons. Neuron 67:294-307.

Dufke C, Sturm M, Schroeder C, Moll S, Ott T, Riess O, Bauer P, Grundmann K (2014) Screening of mutations in GNAL in sporadic dystonia patients. Movement Disorders 29:1193-1196.

Eskow Jaunarajs KL, Scarduzio M, Ehrlich ME, McMahon LL, Standaert DG (2019) Diverse Mechanisms Lead to Common Dysfunction of Striatal Cholinergic Interneurons in Distinct Genetic Mouse Models of Dystonia. J Neurosci 39:7195-7205.

França C, de Andrade DC, Teixeira MJ, Galhardoni R, Silva V, Barbosa ER, Cury RG (2018) Effects of cerebellar neuromodulation in movement disorders: A systematic review. Brain Stimulation.

Fremont R, Tewari A, Khodakhah K (2015) Aberrant Purkinje cell activity is the cause of dystonia in a shRNA-based mouse model of Rapid Onset Dystonia- Parkinsonism Rachel. Neurobiol Disorders 82:200-212.

Fremont R, Tewari A, Angueyra C, Khodakhah K (2017) A role for cerebellum in the hereditary dystonia DYT1. elife.

Fuchs T, Ozelius LJ (2013) Genetics in dystonia: An update topical collection on movement disorders. Current Neurology and Neuroscience Reports.

Fuchs T, Saunders-Pullman R, Masuho I, Luciano MS, Raymond D, Factor S, Lang AE, Liang TW, Trosch RM, White S, Ainehsazan E, Hervé D, Sharma N, Ehrlich ME, Martemyanov KA, Bressman SB, Ozelius LJ (2013) Mutations in GNAL cause primary torsion dystonia. Nature Genetics 45:88-92.

Fujita K, Eidelberg D (2017) Imbalance of the direct and indirect pathways in focal dystonia: a balanced view. Brain 140:3069-3080.

Gallea C et al. (2013) Cerebellar rTMS stimulation may induce prolonged clinical benefits in essential tremor, and subjacent changes in functional connectivity: An open label trial. Brain Stimulation 6:175-179.

Georgescu EL, Georgescu IA, Zahiu DC, Morozan VP, Pana A, Zagrean A-m, Popa D, Zahiu CDM, Pană AŞ, Georgescu IA, Georgescu EL, Şteopoaie AR, Popa D, Zăgrean A-M, Morozan VP (2018) Oscillatory cortical 
activity in an animal model of dystonia caused by cerebellar dysfunction. Frontiers in Cellular Neuroscience 12:1-23.

Hallett M (2006) Pathophysiology of Dystonia. J Neural Transm (2006) 70:485-488.

Hamada M, Strigaro G, Murase N, Sadnicka A, Galea JM, Edwards MJ, Rothwell JC (2012) Cerebellar modulation of human associative plasticity. J Physiol 590:2365-2374.

Hendrix CM, Vitek JL (2012) Toward a network model of dystonia. Annals of the New York Academy of Sciences.

Hensch TK, Ogawa N, Hirono M, Yamada M, Miyamoto H, Hattori M, Yamaguchi N, Mikoshiba K, Hisatsune C, Ohshima T, Sugawara T, Ebisui E (2013) IP3R1 deficiency in the cerebellum/brainstem causes basal ganglia-independent dystonia by triggering tonic Purkinje cell firings in mice. Frontiers in Neural Circuits.

Huang YZ, Edwards MJ, Rounis E, Bhatia KP, Rothwell JC (2005) Theta burst stimulation of the human motor cortex. Neuron 45:201-206.

Hubsch C, Roze E, Popa T, Russo M, Balachandran A, Pradeep S, Mueller F, Brochard V, Quartarone A, Degos B, Vidailhet M, Kishore A, Meunier S (2013) Defective cerebellar control of cortical plasticity in writer's cramp. Brain : a journal of neurology 136:2050-2062.

Huebl J, Poshtiban A, Brücke C, Siegert S, Bock A, Koziara H, Kmiec T, Rola R, Mandat T, Kühn AA (2018) Subthalamic and pallidal oscillatory activity in patients with Neurodegeneration with Brain Iron Accumulation type I (NBIA-I). Clinical Neurophysiology.

Ichinohe N, Mori F, Shoumura K (2000) Short communication A di-synaptic projection from the lateral cerebellar nucleus to the laterodorsal part of the striatum via the central lateral nucleus of the thalamus in the rat. Brain Research 880:191-197.

Isaksen TJ, Kros L, Vedovato N, Holm TH, Vitenzon A, Gadsby DC, Khodakhah K, Lykke-Hartmann K (2017) Hypothermia-induced dystonia and abnormal cerebellar activity in a mouse model with a single diseasemutation in the sodium-potassium pump. PLoS Genetics 13.

Iwata NK, Ugawa Y (2005) The effects of cerebellar stimulation on the motor cortical excitability in neurological disorders: A review. Cerebellum 4:218-223.

Jannati A, Block G, Oberman LM, Rotenberg A, Pascual-Leone A (2017) Interindividual variability in response to continuous theta-burst stimulation in healthy adults. Clinical Neurophysiology 128:2268-2278.

Jinnah HA, Sepkuty JP, Ho T, Yitta S, Drew T, Rothstein JD, Hess EJ (2000) Calcium channel agonists and dystonia in the mouse. Mov Disord 15:542-551.

Kaji R, Bhatia K, Graybiel AM (2017) Pathogenesis of dystonia: is it of cerebellar or basal ganglia origin? Journal of Neurology, Neurosurgery \& Psychiatry:jnnp-2017-316250.

Koch G, Porcacchia P, Ponzo V, Carrillo F, Cáceres-Redondo MT, Brusa L, Desiato MT, Arciprete F, Di Lorenzo F, Pisani A, Caltagirone C, Palomar FJ, Mir P (2014) Effects of two weeks of cerebellar theta burst stimulation in cervical dystonia patients. Brain Stimulation 7:564-572.

Koch G et al. (2008) Clinical Neurophysiology Changes in intracortical circuits of the human motor cortex following theta burst stimulation of the lateral cerebellum. Clinical Neurophysiology 119:2559-2569.

Köhling R, Koch UR, Hamann M, Richter A (2004) Increased excitability in cortico-striatal synaptic pathway in a model of paroxysmal dystonia. Neurobiology of Disease 16:236-245.

LeDoux MS, Lorden JF, Ervin JM (1993) Cerebellectomy eliminates the motor syndrome of the genetically dystonic rat. Exp Neurol 120:302-310.

LeDoux MS, Lorden JF, Meinzen-Derr J (1995) Selective elimination of cerebellar output in the genetically dystonic rat. Brain Res 697:91-103.

Lehéricy S, Tijssen MAJ, Vidailhet M, Kaji R, Meunier S (2013) The anatomical basis of dystonia: Current view using neuroimaging. Movement Disorders 28:944-957.

Linssen MW, Gaalen JV, Munneke MAM, Hoffland BS, Hulstijn W, Warrenburg BPCVD, Van Gaalen J, Munneke MAM, Hoffland BS, Hulstijn W, Van De Warrenburg BPC, Van De Warrenburg BPC (2015) A single session of cerebellar theta burst stimulation does not alter writing performance in writer's cramp. Brain : a journal of neurology:1-5.

Meunier S, Roze E, Kishore A, Hubsch C, Popa T, Hubsch C, Roze E, Kishore A (2015) Reply: A single session of cerebellar theta burst stimulation does not alter writing performance in writer's cramp. Brain 138:e356.

Neychev VK, Fan X, Mitev VI, Hess EJ, Jinnah HA (2008) The basal ganglia and cerebellum interact in the expression of dystonic movement. Brain 131:2499-2509. 
Neychev VK, Gross RE, Lehéricy S, Hess EJ, Jinnah HA (2011) The functional neuroanatomy of dystonia. In: Neurobiology of Disease.

Paz R, Pelletier JG, Bauer EP, Paré D (2006) Emotional enhancement of memory via amygdala-driven facilitation of rhinal interactions. Nature neuroscience 9:1321-1329.

Pelosi A, Menardy F, Popa D, Girault J-A, Hervé D (2017) Heterozygous Gnal Mice Are a Novel Animal Model with Which to Study Dystonia Pathophysiology. The Journal of Neuroscience 37:6253-6267.

Perrin E, Venance L (2019) Bridging the gap between striatal plasticity and learning. Curr Opin Neurobiol 54:104112.

Pizoli CCECCE, Jinnah HAH, Billingsley MLMML, Hess EEJ (2002) Abnormal cerebellar signaling induces dystonia in mice. The Journal of neuroscience : 22:7825-7833.

Popa T, Russo M, Meunier S (2010) Long-lasting inhibition of cerebellar output. Brain Stimul 3:161-169.

Popa T, Velayudhan B, Hubsch C, Pradeep S, Roze E, Vidailhet M, Meunier S, Kishore A (2013) Cerebellar processing of sensory inputs primes motor cortex plasticity. Cereb Cortex 23:305-314.

Popa T, Hubsch C, James P, Richard A, Russo M, Pradeep S, Krishan S, Roze E, Meunier S, Kishore A (2018) Abnormal cerebellar processing of the neck proprioceptive information drives dysfunctions in cervical dystonia. Scientific Reports.

Prudente CN, Hess EJ, Jinnah HA (2014) Dystonia as a network disorder: What is the role of the cerebellum? Neuroscience 260:23-35.

Raike RS, Pizoli CE, Weisz C, van den Maagdenberg AMJM, Jinnah HA, Hess EJ (2013) Limited regional cerebellar dysfunction induces focal dystonia in mice. Neurobiology of disease 49:200-210.

Sciamanna G et al. (2012) Cholinergic Dysfunction Alters Synaptic Integration between Thalamostriatal and Corticostriatal Inputs in DYT1 Dystonia. Journal of Neuroscience 32:11991-12004.

Simonyan K, Cho H, Hamzehei Sichani A, Rubien-Thomas E, Hallett M (2017) The direct basal ganglia pathway is hyperfunctional in focal dystonia. Brain 140:3179-3190.

Smith Y, Galvan A, Ellender TJ, Doig N, Villalba RM, Huerta- I, Wichmann T, Bolam JP (2014) The thalamostriatal system in normal and diseased states. Systems neuroscince 8:1-18.

Suppa A, Huang YZ, Funke K, Ridding MC, Cheeran B, Lazzaro VD, Ziemann U, Rothwell JC (2016) Ten Years of Theta Burst Stimulation in Humans : Established Knowledge, Unknowns and Prospects.

Ulug AM, Vo A, Argyelan M, Tanabec L, Schiffera WK, Deweya S, Dauerc WT, Eidelberg D (2011) Cerebellothalamocortical pathway abnormalities in torsinA DYT1 knock-in mice. Proceedings of the National Academy of Sciences 108:6638-6643.

Vemula SR, Puschmann A, Xiao J, Zhao Y, Rudzinska M, Frei KP, Truong DD, Wszolek ZK, LeDoux MS (2013) Role of Galpha(olf) in familial and sporadic adult-onset primary dystonia. Hum Mol Genet 22:2510-2519.

White JJ, Sillitoe RV (2017) Genetic silencing of olivocerebellar synapses causes dystonia-like behaviour in mice. Nat Commun 8:14912. 


\section{Animals}

All experiments were performed in accordance with the guidelines of the European Community Council

Directives. Gnal+/- mice were mated with C57BL/6J mice to produce male and female Gnal+/- and WT

littermates. Animals (males and females Gnal+/- and WT aged 3 to 7-months-old) were kept at a

constant room temperature and humidity on $12 \mathrm{~h}$ light/dark cycle and with ad libitum access to water and food. All the motor control experiments were performed in males and females and recordings were performed in freely moving mice.

\section{Open-field activity}

Mice were placed in a circle arena made of plexiglass with $38 \mathrm{~cm}$ diameter and $15 \mathrm{~cm}$ height (Noldus, min with the experimenter out of its view. The position of centre of gravity of mice was tracked using an algorithm programmed in Python 3.5 and the OpenCV 4 library. Each frame obtained from the openfields' videos were analysed according to the following process: Open-field area was selected and extracted in order to be transformed into a grayscale image. Then, a binary threshold was applied on this grayscale image to differentiate the mouse from the white background. To reduce the noise induced by the recording cable or by particles potentially present in the Open-field, a bilateral filter and a frequency compared to the mouse. Finally, the OpenCV implementation of Canny algorithm was applied to detect the contours of the mouse, the position of the mouse was computed as mouse's centre of mass. The distance travelled by the mouse between two consecutive frames was calculated as the 
from pixel unit to centimetres. The total distance travelled was obtained by summing the previously calculated distances over the course of the entire Open-field session. The speed was computed as the variation of position of centre points on two consecutive frames divided by the time between these frames (the inverse of the number of frames per seconds). This speed was then averaged by creating sliding windows of 1 second. After each session, faecal boli were removed and the floor was wiped clean with a damp cloth and dried after the passing of each mouse.

\section{Horizontal bar test}

Motor coordination and balance were estimated with the horizontal bar test which consists of a linear horizontal bar extended between two supports (length: $90 \mathrm{~cm}$, diameter: $1.5 \mathrm{~cm}$, height: $40 \mathrm{~cm}$ from a padded surface). The mouse is placed in one of the sides of the bar and released when all four paws gripped it. The mouse must cross the bar from one side to other and latencies before falling are measured in a single trial session with a 3-min cut-off period.

\section{Vertical pole test}

Motor coordination was estimated with the vertical pole test. The vertical pole $(51 \mathrm{~cm}$ in length and 1.5 $\mathrm{cm}$ in diameter) was wrapped with white masking tape to provide a firm grip. Mice were placed heads up near the top of the pole and released when all four paws gripped the pole. The bottom section of the pole was fixated to its home-cage with the bedding present but without littermates. When placed on the pole, animals naturally tilt downward and climb down the length of the pole to reach their home cage. The time taken before going down to the home-cage with all four paws was recorded. A 20 sec habituation was performed before placing the mice at the top of the pole. The test was given in a single trial session with a 3-min cut-off period. 


\section{Gait test}

Motor coordination was also evaluated by analysing gait patterns. Mouse footprints were used to estimate foot opening angle and hindbase width, which reflects the extent of muscle loosening. The mice crossed an illuminated alley, $70 \mathrm{~cm}$ in length, $8 \mathrm{~cm}$ in width, and $16 \mathrm{~cm}$ in height, before entering a dark box at the end. Their hind paws were coated with nontoxic water-soluble ink and the alley floor was covered with sheets of white paper. To obtain clearly visible footprints, at least 3 trials were conducted. The footprints were then scanned and examined with the Dvrtk software (Jean-Luc Vonesch, IGBMC). The stride length was measured with hindbase width formed by the distance between the right and left hind paws.

\section{Grid test}

The grid test is performed to measure the strength of the animal. It consists of placing the animal on a grid which tilts from a horizontal position of $0^{\circ}$ to $180^{\circ}$. The animal is registered by the side and the time it drops is measured. The time limit for this experiment is 30 seconds. In those cases where the mice climbed up to the top of grid, a maximum latency of 30 seconds was applied.

\section{Fixed speed rotarod}

Motor coordination, postural stability and fatigue were estimated with the rotarod (mouse rotarod, Ugo Basile). Facing away from the experimenter's view, the mice placed on top of the plastic roller were tested at constant speeds $(5,10,15,20$ and 25 r.p.m.). Latencies before falling were measured for up to $3 \mathrm{~min}$ in a single trial session.

\section{Surgery}


554 Two surgeries were performed. During the first surgery, AAV2/1.hSyn.ChR2(H134R)-eYFP.WPRE.hGH 555 (700nl) was injected into the deep cerebellar nuclei of the Gnal+/- and WT mice (dentate nucleus, DN: $556-6 \mathrm{~mm} \mathrm{AP}, \pm 2.3 \mathrm{~mm} \mathrm{ML},-2.4 \mathrm{~mm}$ depth from dura). After 3 weeks, implantation surgery was 557 performed. For both surgeries, the mice were anesthetized either with a mixture of ketamine/xylazine 558 or with a mixture of isoflurane and $\mathrm{O} 2$ ( $3 \%$ for induction, $1,7 \%$ for maintenance). Injections with 559 buprenorphine $\left(0.05 \mathrm{mg} / \mathrm{kg}\right.$, s.c.) were performed to control pain, and core temperature $\left(37^{\circ} \mathrm{C}\right)$ was 560 maintained with a heating pad. The mice were fixed in a stereotaxic apparatus (David Kopf Instruments, 561 USA). After a local midline lidocaine injection s.c. $(2 \%, 1 \mathrm{ml})$, a medial incision was performed exposing the skull. Small craniotomies were drilled above the recording sites and above the optic fibre location 563 (above the virus injection site) and then the electrodes were stereotaxically lowered inside the brain. This allowed us to record in the left motor cortex (M1) (AP +2 mm and $-2 \mathrm{~mm} \mathrm{ML} \mathrm{from} \mathrm{the} \mathrm{Bregma),}$ 565 ventro-lateral thalamus (VAL) $(-1.34 \mathrm{~mm} \mathrm{AP,} \mathrm{ML=-1.00} \mathrm{mm}$ and $\mathrm{DV}=-3.4 \mathrm{~mm}$ depth from the dura) and centro-lateral thalamus $(\mathrm{CL})(\mathrm{AP}$ at $-1.58 \mathrm{~mm}, \mathrm{ML}=-0.8 \mathrm{~mm}, \mathrm{DV}=-3.00 \mathrm{~mm}$ depth from the dura). The mice were implanted with bundles of extracellular electrodes for each recording site. The ground wire was placed on the surface of the cerebellum. Super Bond (Dental Adhesive Resin Cement, Sun Medical CO, Japan) was applied on the surface of the skull to strengthen the connection between the bone and the cement. Then, the cannulas and ground wire were fixed with dental cement (Pi-Ku-Plast HP 36, Bredent $\mathrm{GmbH}, \mathrm{Germany})$. The bundles of 8 electrodes were made in house by folding and twisting nichrome wire with 0.005 inches diameter (Kanthal RO-800) (Menardy et al., 2019). The bundles were placed 573 inside guide cannulas $(8-10 \mathrm{~mm}$ length and $0.16-0.18 \mathrm{~mm}$ inner diameter, Coopers Needle Works 574 Limited, UK) glued (Loctite universal glue) to an electrode interface board (EIB-16; Neuralynx, Bozeman, MT, USA) with 1 wire for each channel and 4 channels for each brain region (M1, CL, VAL), extending 0.5 
and then the EIB was secured in place by dental cement. A gold solution (cyanure-free gold solution, Sifco, France) was used for gold plating and the impedance of each electrode was set to $200-500 \mathrm{k} \Omega$.

\section{Manipulations of cerebellar output}

Because the cerebellar nuclei sends projections in the contralateral thalamus that then connects with the M1 (Teune et al., 2004) optogenetic stimulations were performed in the contralateral cerebellar DN (left M1 and right DN). Light-induced excitation of the cerebellar-projection neurons was elicited by using a LED driver (Mightex Systems ${ }^{\circledR}$ ) through optical fibres radiating blue light $(470 \mathrm{~nm})$ unilaterally implanted into the deep cerebellar nuclei (light intensity of $\sim 1.5 \mathrm{~mW} / \mathrm{mm} 2$ ). Optogenetic stimulations of the DN $(1000 \mathrm{~mA}, 100 \mathrm{~ms}, 0.25 \mathrm{~Hz}$ or theta-burst stimulation $1000 \mathrm{~mA}, 20 \mathrm{~ms}, 8,33 \mathrm{~Hz}$, applied for $2 \times 40 \mathrm{~s}$ with a 2 min pause in between) were performed before and after triggering the dystonic attacks by an oxotremorine methiodide (oxotremorine $\mathrm{M}$ ) intraperitoneal injection.

\section{Electrophysiological recordings}

The recordings begun after at least 3 days of recovery and were performed on awake freely moving mice using a 16-channel acquisition system with a sampling rate of $25 \mathrm{kHz}$ (Tucker Davis Technology System 3, Tucker-Davis Technologies, Alachua, FL, USA). We performed 60 minutes baseline recording in an open-field, followed by a 60 min recording after a saline injection. Gnal+/- and WT mice were then injected intraperitoneally with oxotremorine methiodide $(0.1 \mathrm{mg} / \mathrm{kg}$, Sigma-Aldrich), dissolved in saline $(\mathrm{NaCl} 0.9 \mathrm{~g} / \mathrm{L})$ and recorded another $60 \mathrm{~min}$ with the same protocol as for saline. Optogenetic stimuli were applied on the DN at low frequency stimuli of $100 \mathrm{~ms}, 1000 \mathrm{~mA}$ and $0.25 \mathrm{~Hz}$. On the next day, theta burst stimulations was implemented. The mice were recorded $60 \mathrm{~min}$ after the saline injection and then 60 min after the oxotremorine $\mathrm{M}$ injection using the same protocol as in baseline day except that 
600

601

602

603

604

605

606

607

608

609

610

611

612

613

614

615

616

617

618

619

620

621

622

623

after 30 minutes 2 theta-burst sessions of 40 sec each with 2 minutes pause in between were applied (a total of 600 pulses for each condition).

Histological verification of the site of optical fibre in DN and verification of the position of the electrodes.

The animals were sacrificed with a single dose of pentobarbital $(100 \mathrm{mg} / \mathrm{kg}$, i.p.). Electrolytic lesions were performed to check the position of the electrodes, mice were perfused with paraformaldehyde and the brains were removed and kept in paraformaldehyde (4\%). After slicing (using a vibratome at $90 \mu \mathrm{m}$ thickness), all sites of the recordings were verified by superposing the atlas (Allen Brain Atlas) on slices, with the closest anatomical landmarks from our lesions used as reference points. (Figure 1.D)

\section{Behavioural Analysis}

Video recordings monitored the motor behaviour of Gnal+/- and WT mice in the open-field. Dystonia severity was estimated using a previously published abnormal movement scoring scale (Jinnah et al., 2000; Calderon et al., 2011; Pelosi et al., 2017) for every 10 min-long block of the recording, after the oxotremorine $\mathrm{M}$ injection was performed. The assessment was blinded for mouse genotype and was done by 2 members of the team. The scale uses the following scores: $0=$ normal motor behavior; $1=$ no impairment, but slightly slowed movements; 2. Mild impairment: occasional abnormal postures and movements; ambulation with slow walk; 3. Moderate impairment: frequent abnormal postures and movements with limited ambulation; 4. Severe impairment: sustained abnormal postures without any ambulation or upright position. In addition, total time of active wakefulness from the total time of recording (active wake percentages, AW\%) was assessed for both states, pre and post oxotremorine and pre and post theta-burst stimulation. Active wake was considered as the state when the mouse is exploring the open-field by walking in any direction and is expressed as a percentage of the total time of 
the recording (Georgescu et al., 2018). We evaluated the impact of theta-burst DN stimulation on the onset of dystonic-like symptoms in saline- and oxotremorine-treated Gnal+/- mice.

\section{Electrophysiological Analysis}

Spike sorting was completed using homemade Matlab scripts (Mathworks, Natick, MA, USA) that are based on k-means clustering on PCA of the spike waveforms (Paz et al., 2006). In order to evaluate the activity of the same cells in similar conditions during experiments, we investigated the change of the firing rate probability in the thalamus and M1 motor cortex during cerebellar DN $100 \mathrm{~ms}$ stimulations after saline or oxotremorine $\mathrm{M}$ administration performed and analyses in one continuous session. The average increase in firing rate during the stimulation was determined by computing the peri-stimulus time histogram (bin: 10ms) of the spikes around the stimulation; the spike count in the histogram was divided by the duration of the stimulation and the number of stimulations administered to yield a firing rate. The acceleration of discharge due to the stimulation was taken as the average spike count during the stimulation subtracted by the baseline (taken as the $300 \mathrm{~ms}$ that preceded the stimulation onset). The response to stimulation was only analysed in cells where at least one bin during the stimulation was larger than 4 times the standard deviation of the baseline values

\section{Statistics}

Figures represent the averages \pm standard error of the mean (SEM). Student T test, Mann-Whitney test, repeated-measure ANOVA and multiple comparisons test was used as appropriate, after testing the normality of the data by D'Agostino and Pearson omnibus normality test. 
646

647

648

649

650

651

652

653

654

655

656

657

658

659

660

661

662

663

664

665

666

667

668

669

670

Figure legends:

Figure 1. Locomotor activity and motor coordination in Gnal+/- mice. (A) Latency to cross the vertical pole; Mann-Whitney test. (B) Latency to cross the horizontal bar; Mann-Whitney test. (C) Latency to fall during the grid test with a 30s cut-off; Mann-Whitney test. (D) Latency to fall during the fixed speed rotarod test; Repeated measure ANOVA. (E) Latency to fall during the fixed speed rotarod test with groups separated by gender and genotype; Welch corrected Student's t test for each speed step, corrected for multitests using Bonferroni's method. (F) Gait width, alternation coefficient, movement linearity, sigma and stride length during the gait test; Mann-Whitney test ${ }^{*} p<0.05 ;{ }^{* *} p<0.01$ (G) Example of heatmaps showing the position of mice during open-field sessions. Average speed $(\mathbf{H})$ and total distance travelled (I) during an open-field session; Mann-Whitney test ${ }^{*} \mathrm{p}<0.05 ;{ }^{* *} \mathrm{p}<0.01$.

Figure 2. Electrophysiology recordings of ventro-lateral VAL and centro-lateral CL thalami nuclei and M1 motor cortex. (A) Picture of a freely moving mouse during a recording coupled with optogenetic DN stimulation. (B) Schematic of experimental design. Guide cannulas with bundles of electrodes were inserted in left M1 (motor cortex), CL (centro-lateral thalamus), VAL (ventro-lateral thalamus); an optic fibre was inserted in the right DN 3 weeks after AAV2/1.hSyn.ChR2(H134R)-eYFP.WPRE.hGH virus was injected. (C) Histology section showing the implantation sites. An atlas map is overlaid on the coronal sections to identify the targeted regions. (D) Left: excerpts of traces and spikes (coloured bars); right: average \pm SEM waveforms of VAL, CL and M1 neurons. (E) Average firing rate in freely moving WT and Gnal+/- mice.

Figure 3. Effect of low-frequency and theta-burst cerebellar stimulations on the firing rate in saline and oxotremorine conditions in VAL, CL and M1 of WT and Gnal+/- mice. On the first day, we examined the 
671

effects of low frequency opto-stimulations (blue line, $100 \mathrm{~ms}, 0.25 \mathrm{~Hz}$ ) on the firing rate of neurons in the various brain regions after saline and oxotremorine administrations. On the following day, the effects of the same low frequency stimulation were compared before and after $\theta$-burst stimulations (20ms, $8,33 \mathrm{~Hz}$, applied for $2 \times 40 \mathrm{~s}$ with a $2 \mathrm{~min}$ pause in between) after saline and oxotremorine administrations. (A) Raster and peristimulus time histogram (PSTH, bin $10 \mathrm{~ms}$ ) for one VAL neuron from a WT mouse before (left) and after (right) theta-burst stimulation in saline condition; the PSTH are normalized to express a firing rate (see Methods). (B) Overlay of the PSTHs from the panel A; the difference between the histograms is filled to evidence the potentiation or depression of the responses. In this case potentiation prevails. See Table 1 for number of cells/mice used. (C) Increase in firing rate (relative to the baseline firing rate) induced by $100 \mathrm{~ms}$ DN nucleus stimulations in WT and Gnal+/animals. (D) Impact of theta-burst stimulations administered in saline condition on the response to 100 ms DN stimulation. Note the absence of potentiation in Gnal+/- mice. (E) (F) same as (A) and (B) respectively, for a VAL neuron from a Gnal+/- mouse before and after theta-burst stimulation in the oxotremorine condition. (G) effect of oxotremorine administration on the response to cerebellar stimulations. (H) Impact of theta-burst stimulations on the response to $100 \mathrm{~ms}$ DN stimulation (same as (D)) in the oxotremorine condition. See Table 2 for corresponding repeated measures ANOVAs. ${ }^{*} p<0.05$, ${ }^{* *} p<0.01,{ }^{* * *} p<0.001$ paired difference between conditions for the cells, ${ }^{\#}<<0.05$ difference between Gnal+/- and WT mice. Error bars represent SEM.

Figure 4. Motor behavior of Gnal+/- (orange) and WT mice (grey). (A) Examples of dystonic postures in Gnal+/- mice following oxotremorine M administration. (B) Average dystonia scores in Gnal+/- and WT mice following oxotremorine $\mathrm{M}$ administration before and after dentate theta-burst stimulation (C) Change of average active wake percentage after one session of DN theta-burst stimulation in Gnal+/and WT mice. Data were analysed by repeated measure ANOVA. ${ }^{* *} p<0.01$ difference between pre and 
695 post theta-burst stimulations. Error bars represent SEM.

696

697 Table 1. Number of cells used in the analysis of baseline firing rate (Figure 2E) and of responses to 698 cerebellar stimulation (Figure 3C,D,G,H).

700 Table 2. Repeated measure ANOVA for the increase in firing rate induced by low-frequency DN 701 stimulations in the VAL and CL thalamus, and motor cortex M1 in saline/oxotremorine conditions and before/after theta-burst stimulations. 
Figure 1
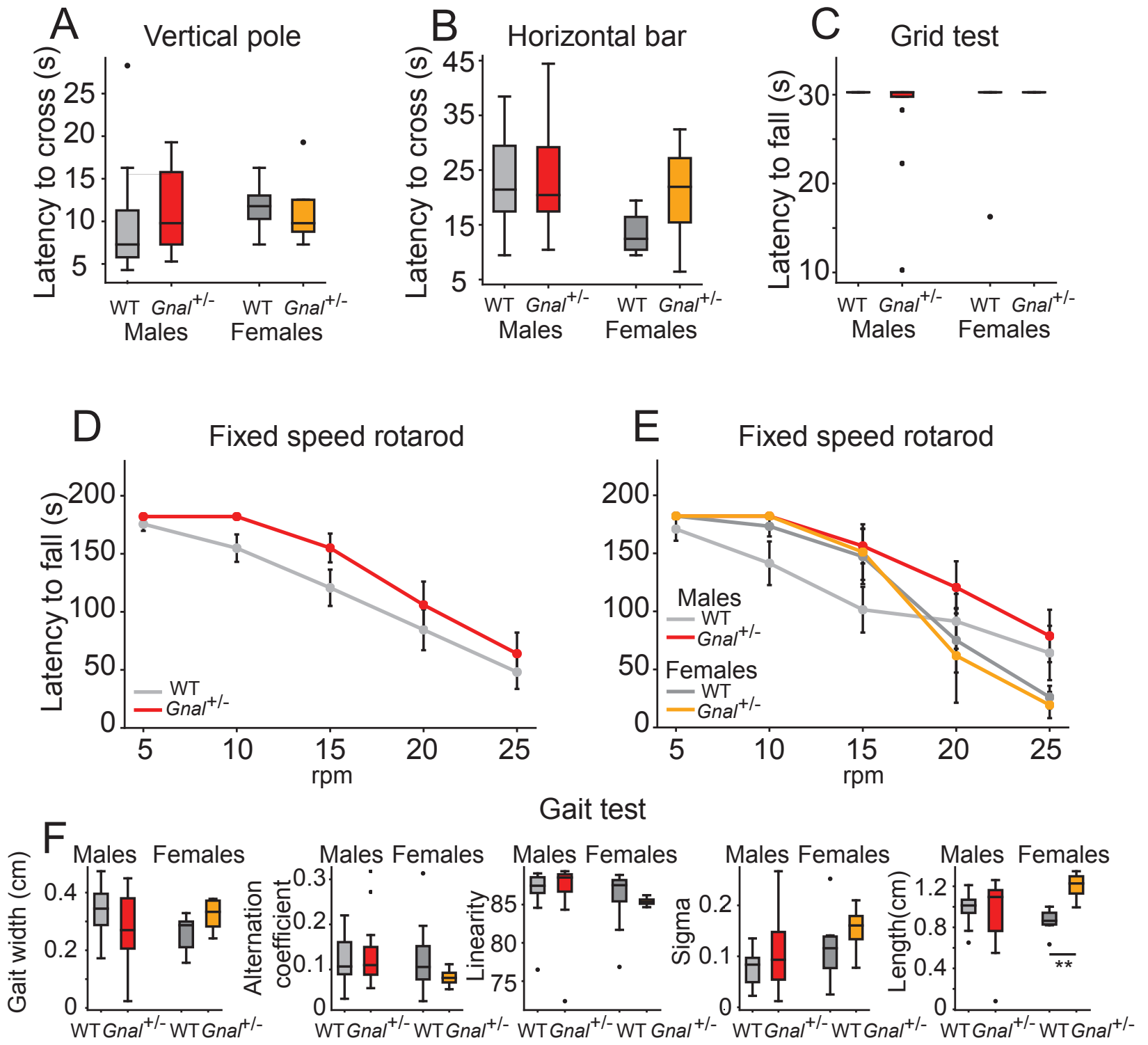

G Open-field examples
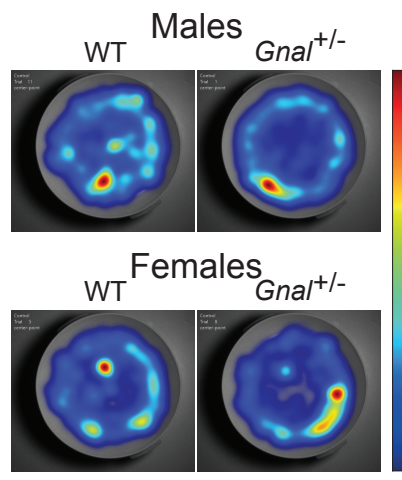

$\mathrm{H}$ Average speed

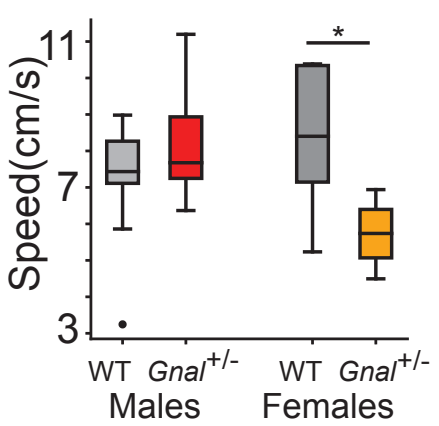

Distance travelled

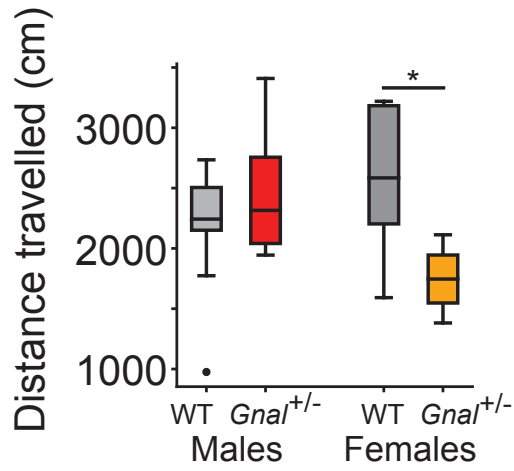


A

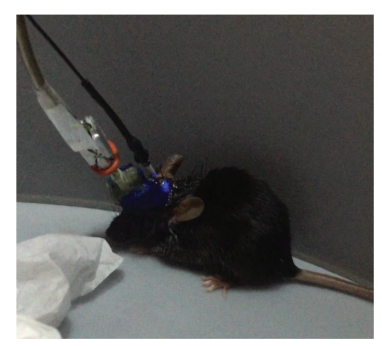

B

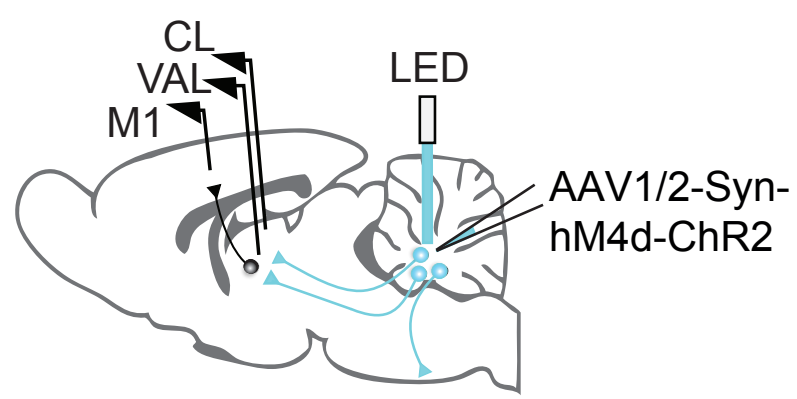

D example of recordings

$\mathrm{M1}$

100uV

VAL
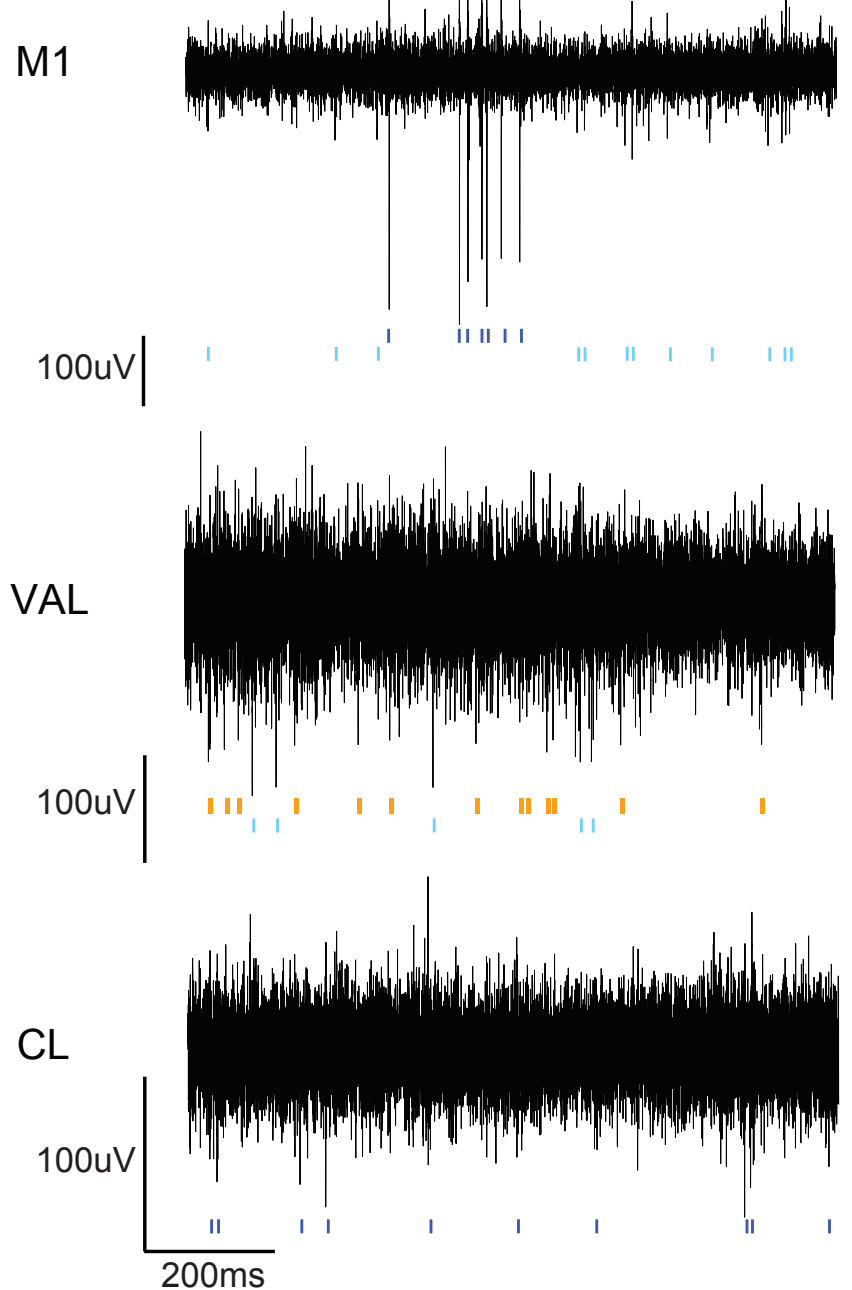

\section{units waveform}

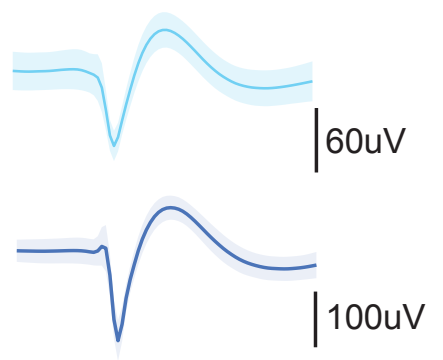

$E$
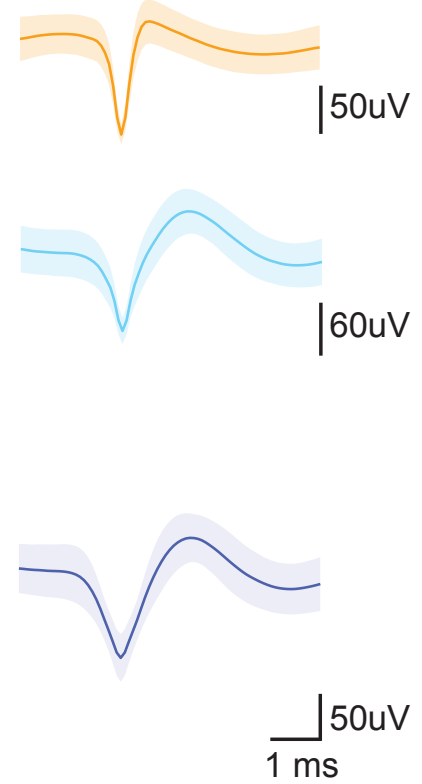
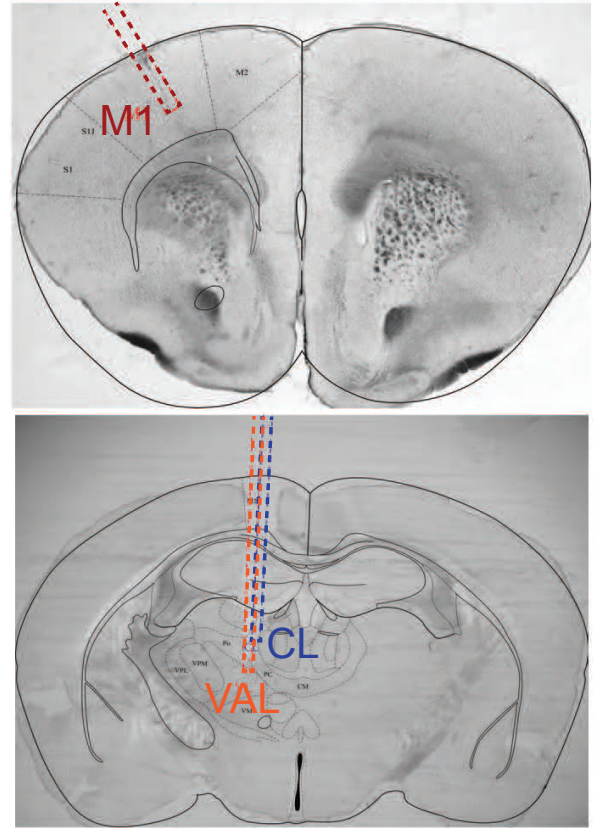

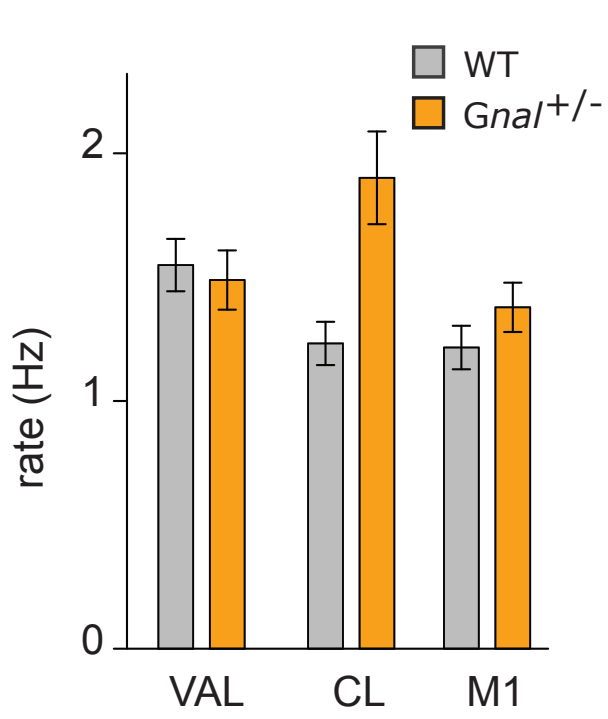


bioRxiv preprint doi: https://doi.org/10.1101/2020.01.29.926170; this version posted February 3, 2020. The copyright holder for this preprint (which was not certified by peer review) is the author/funder, who has granted bioRxiv a license to display the preprint in perpetuity. It is made available under aCC-BY 4.0 International license.

Figure 3

A

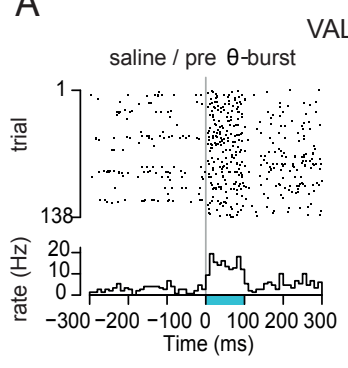

VAL (WT)

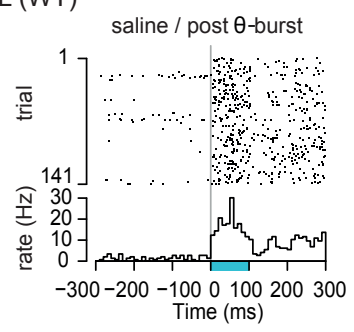

B

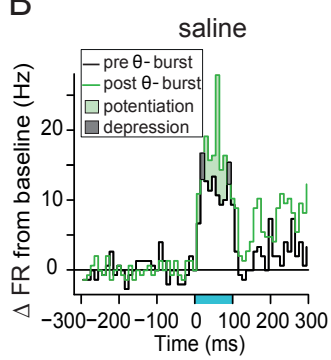

C

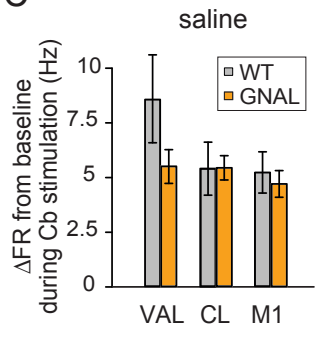

G oxotremorine - saline

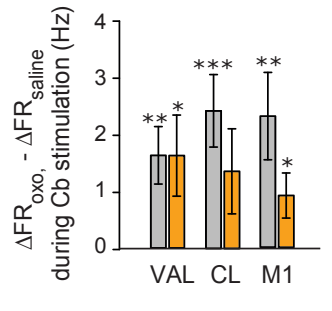

D saline

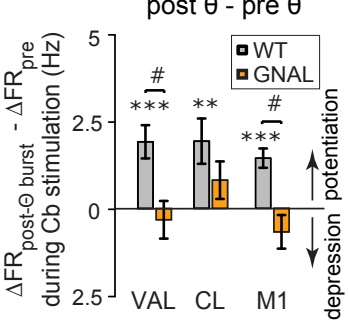

oxotremorine
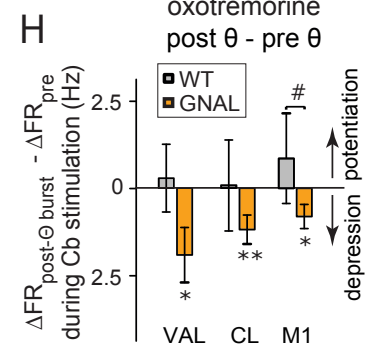

$F$

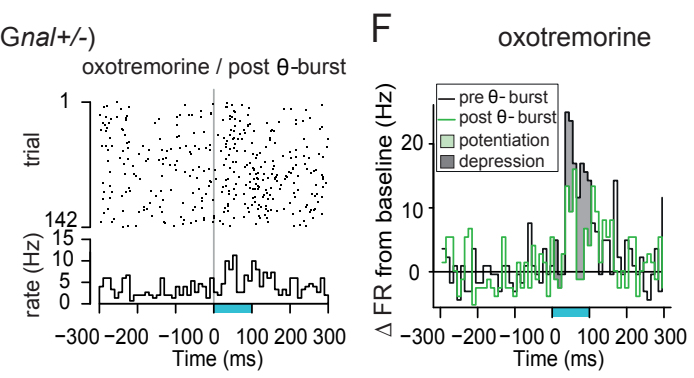

$\left.\begin{array}{l}5 \\ 0\end{array}\right]$ $-300-200-1000100200300$
Time (ms)

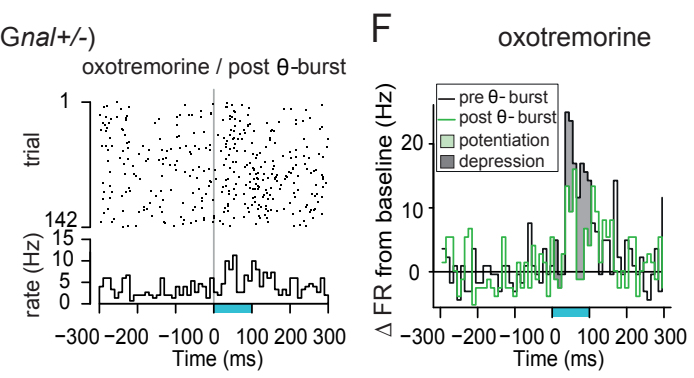
Time (ms)
-1000100200300
Time (ms) 
Figure 4

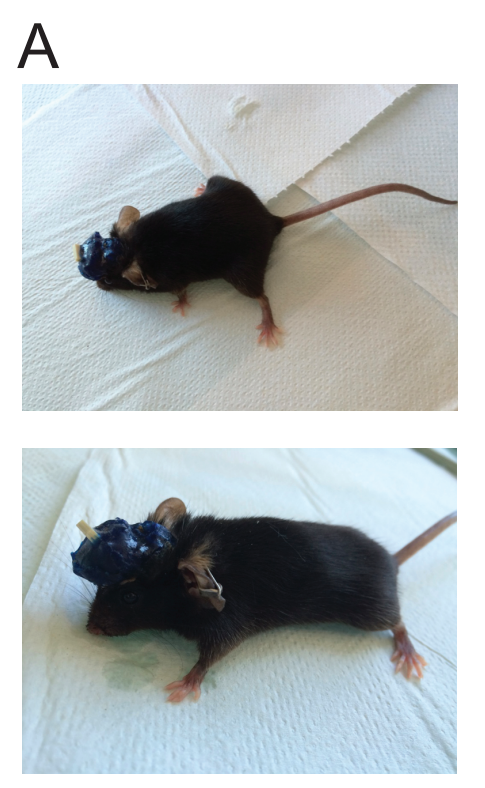

C

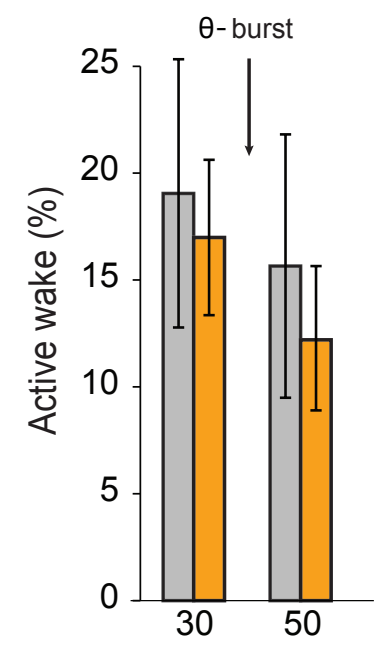

Time (min after injection)

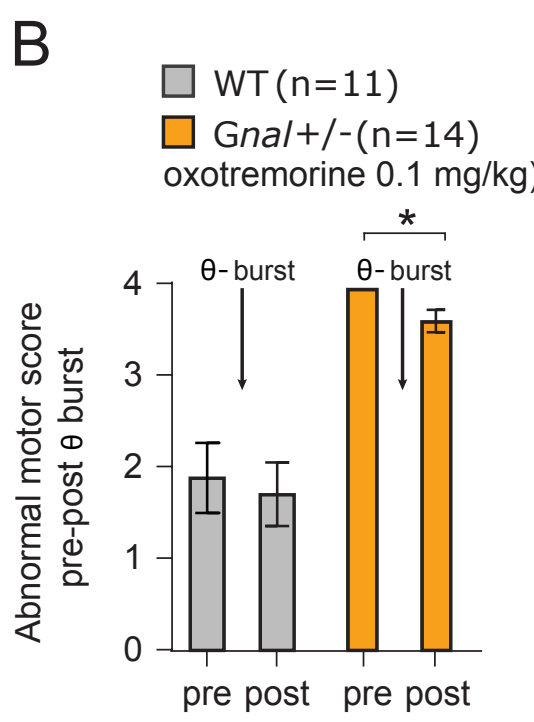

oxotremorine

$\square \mathrm{WT}(\mathrm{n}=11)$

$\square \mathrm{Gnal}^{+/-}(\mathrm{n}=14)$

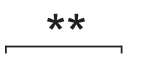

$\theta$-burst

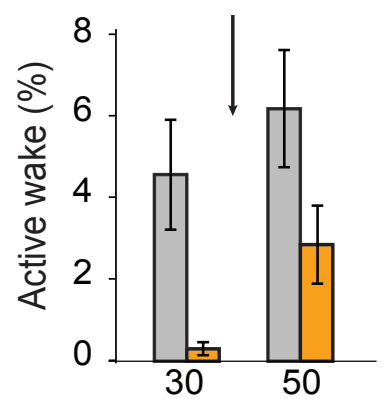

Time (min after injection) 
bioRxiv preprint doi: https://doi.org/10.1101/2020.01.29.926170; this version posted February 3, 2020. The copyright holder for this preprint (which was not certified by peer review) is the author/funder, who has granted bioRxiv a license to display the preprint in perpetuity. It is made available under aCC-BY 4.0 International license.

Table 1

\begin{tabular}{|c|c|c|c|c|c|c|c|c|}
\cline { 2 - 9 } \multicolumn{1}{c|}{} & \multicolumn{3}{c|}{ FR analysis } & \multicolumn{3}{c|}{ Cb stim analysis } \\
\cline { 2 - 10 } \multicolumn{1}{c|}{} & \# cells & \multicolumn{2}{c|}{ \# mice } & \multicolumn{2}{c|}{ \# cells } & \multicolumn{2}{c|}{ \# mice } \\
\hline region & WT & HET & WT & HET & WT & HET & WT & HET \\
\hline VAL & 179 & 221 & 8 & 10 & 23 & 21 & 3 & 4 \\
CL & 236 & 194 & 12 & 11 & 31 & 27 & 5 & 3 \\
M1 & 210 & 237 & 13 & 12 & 37 & 54 & 5 & 5 \\
\hline
\end{tabular}


bioRxiv preprint dol: https://doi.org/10.1101/2020.01.29.926170; this version posted February 3, 2020. The copyright holder for this reprint (which was not certified by peer review) is the author/funder, who has granted bioRxiv a license to display the preprint in perpetuity. It is made available under aCC-BY 4.0 International license.

Table 2

REGION RECORDED

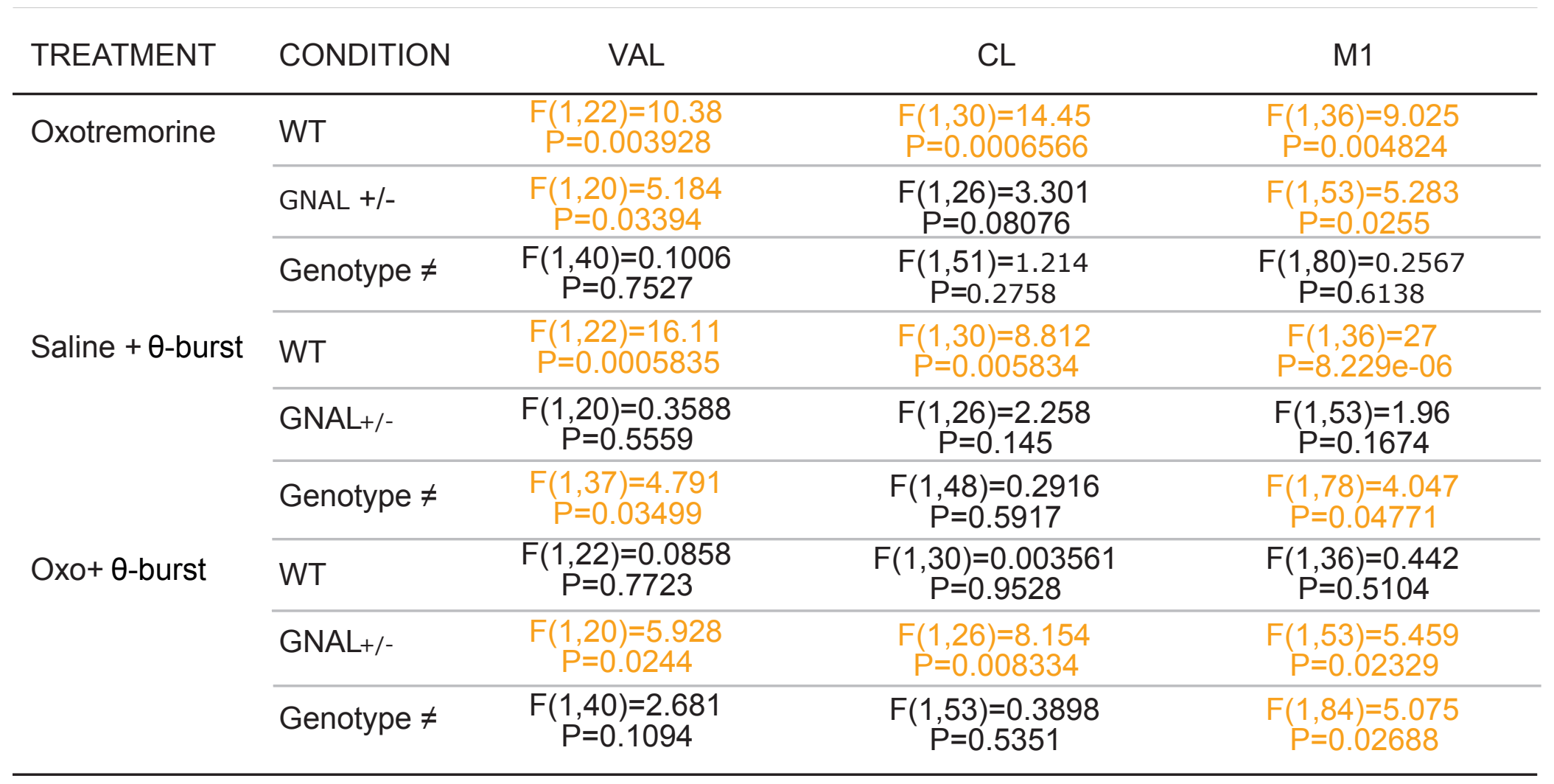

